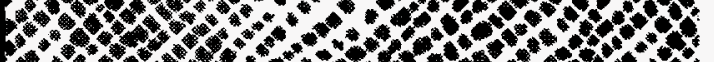

$12 / 23-95050$

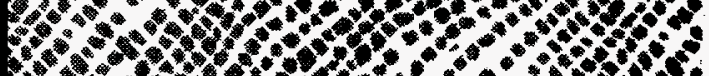

ARM-95-001

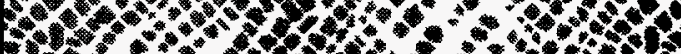

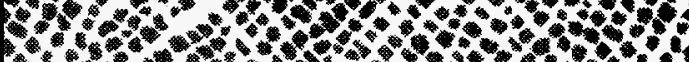

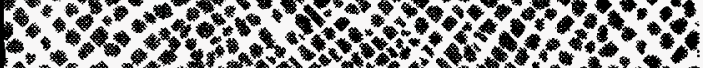

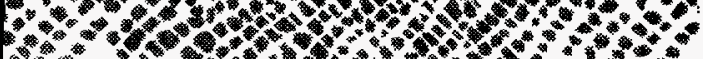

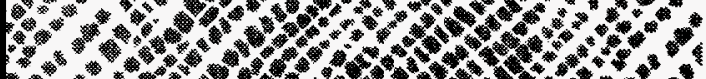

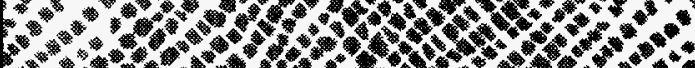

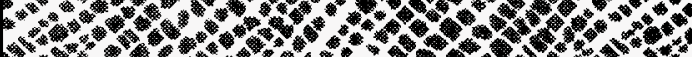

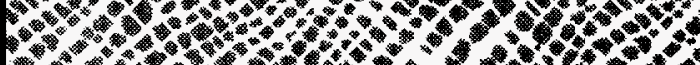

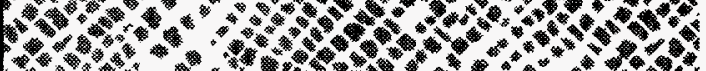

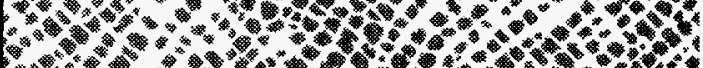

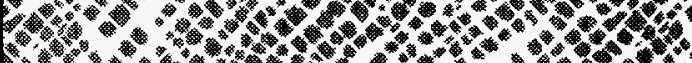

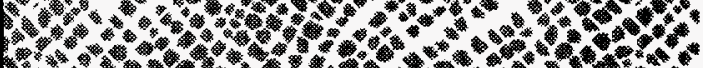

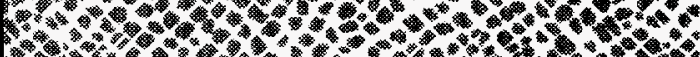
Fo.

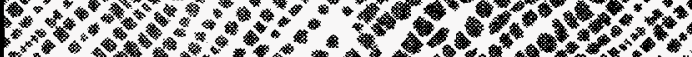

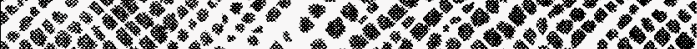

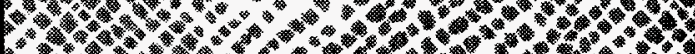

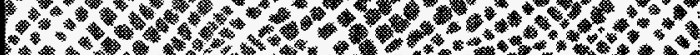

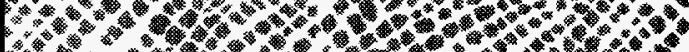
F.t.

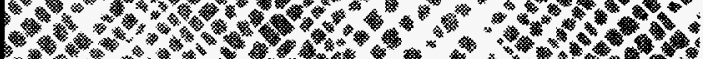

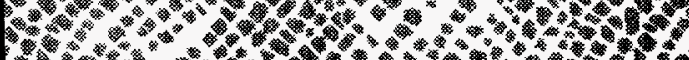
W.

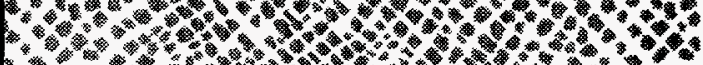

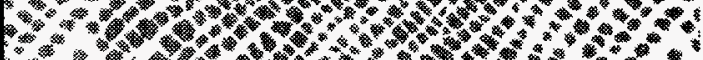

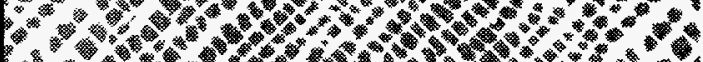

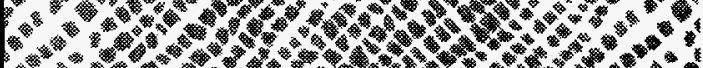
3.

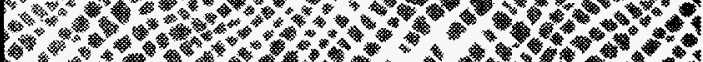

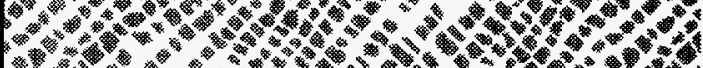

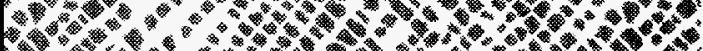

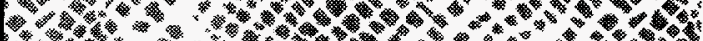

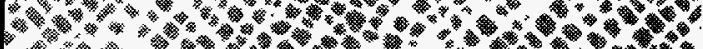

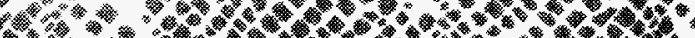

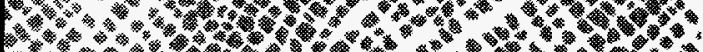

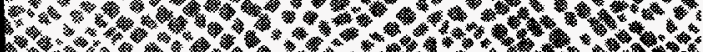

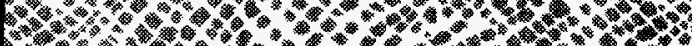

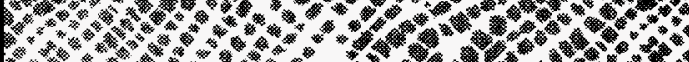

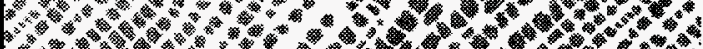

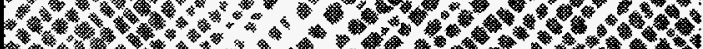

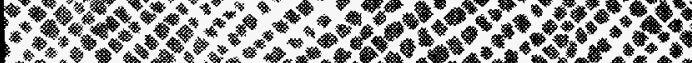

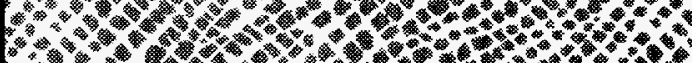

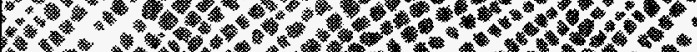

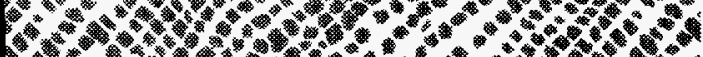

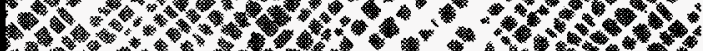

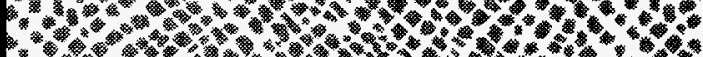

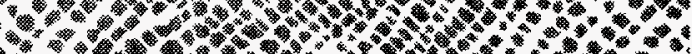

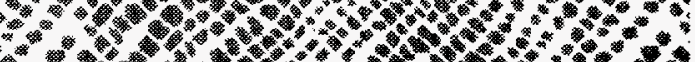

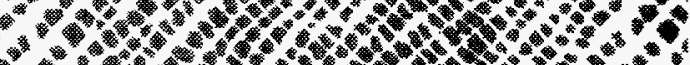

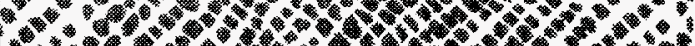

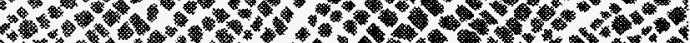

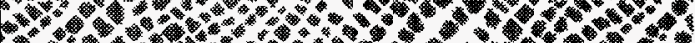

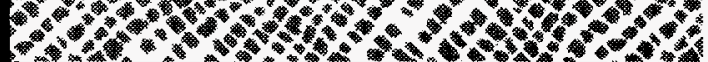

\section{Site Scientific Mission Plan for the Southern Great Plains CART Site}

\author{
January-June 1995
}

Prepared for the U.S. Department of Energy under Contract W-31-109-ENG-38

Site Program Manager Office Environmental Research Division Argonne National Laboratory Argonne, IL 60439

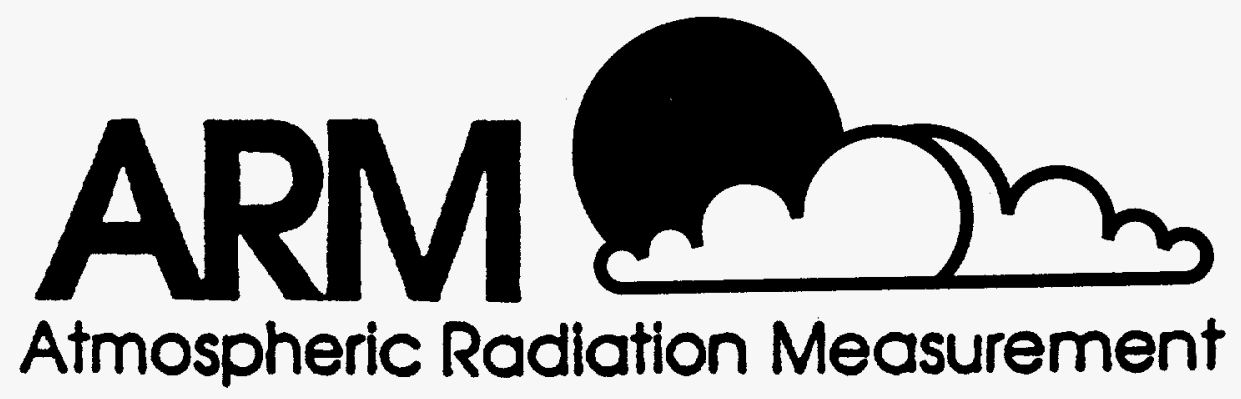

DISTRIBUTION OF THIS DOCUMENT IS UNLIMITED 


\section{DISCLAIMER}

This report was prepared as an account of work sponsored by an agency of the United States Government. Neither the United States Government nor an agency thereof, nor any of their employees, makes any warranty, express or implied, or assumes any legal liability or responsibility for the accuracy, completeness, or usefulness of any information, apparatus, product, or process disclosed, or represents that its use would not infringe privately owned rights. Reference herein to any specific commercial product, process, or service by trade name, trademark, manufacturer, or otherwise, does not necessarily constitute or imply its endorsement, recommendation, or favoring by the United States Government or any agency thereof. The views and opinions of authors expressed herein do not necessarily state or reflect those of the United States Government or any agency thereof.

Publishing support services were provided by Argonne's Information and Publishing Division.

Reproduced directly from the best available copy.

Available to DOE and DOE contractors from the Office of Scientific and Technical Information, P.O. Box 62, Oak Ridge, TN 37831; prices available from (615) 576-8401.

Available to the public from the National Technical Information Service, U.S. Department of Commerce, 5285 Port Royal Road, Springfield, VA 22161. 


\section{DISCLAIMER}

Portions of this document may be illegible in electronic image products. Images are produced from the best available original document. 


\title{
Site Scientific Mission Plan for the Southern Great Plains CART Site
}

\author{
January-June 1995
}

December 1994

Jeanne M. Schneider and Peter J. Lamb

Cooperative Institute for Mesoscale Meteorological Studies

The University of Oklahoma

Norman, Oklahoma 73019

and

Douglas L. Sisterson

Environmental Research Division

Argonne National Laboratory

Argonne, Illinois 60439

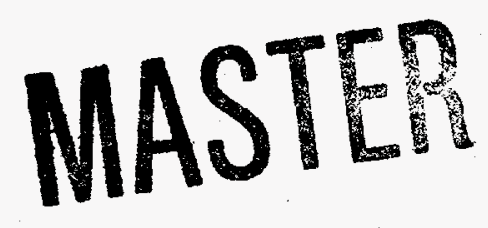

Work supported by United States Department of Energy,

Office of Energy Research,

Office of Health and Environmental Research 


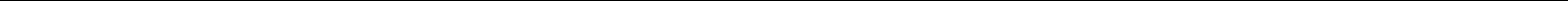




\section{CONTENTS}

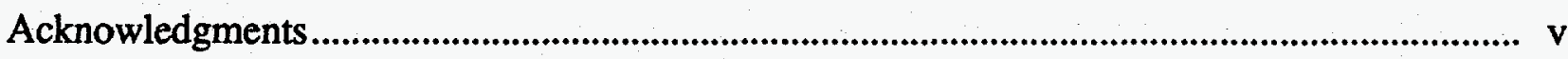

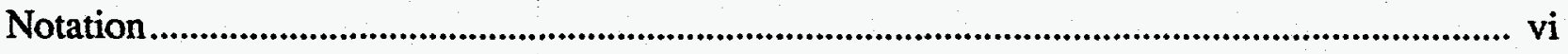

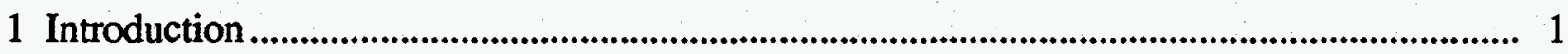

2 Priorities for Site Activities........................................................................................ 2

3 Summary of Scientific Goals .......................................................................................... 3

4 Establishment of Routine Site Operations ............................................................................... 8

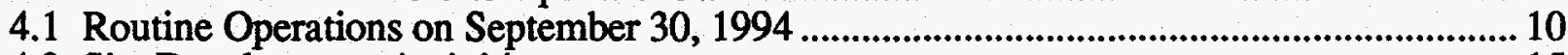

4.2 Site Development Activities ............................................................................................ 15

4.3 Routine Operations and Measurements Expected to Be in Place by June 30, 1995 .......... 40

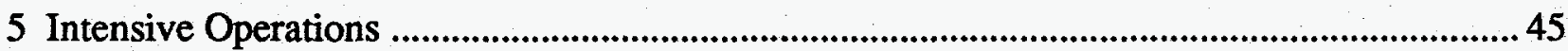

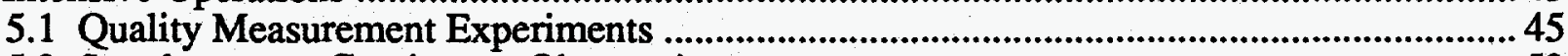

5.2 Supplement to Continuous Observations............................................................................... 52

5.3 Support for the Instrument Development Programs, Guest Instruments,

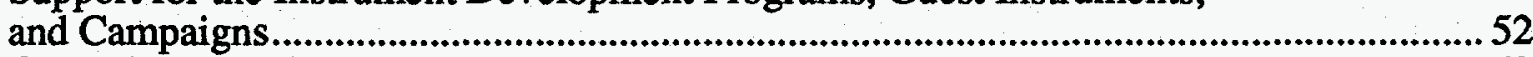

5.4 Campaign Planning ....................................................................................................................... 52

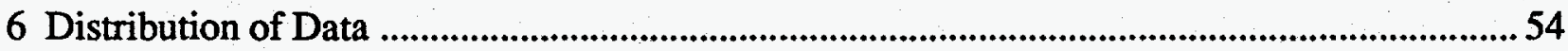

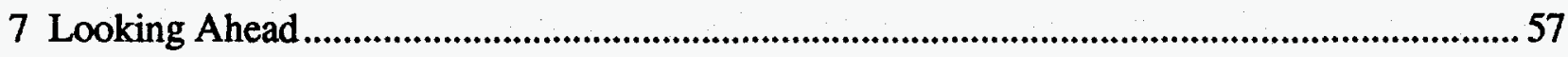

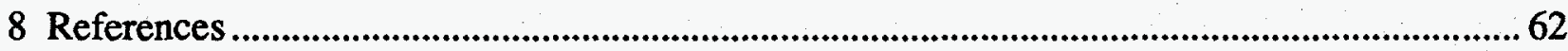

\section{FIGURES}

1 Overall View of the SGP CART Site

2 Site Development Activities to Establish Routine Operations ................................................2 28

3 Site Development Activities to Install Central Facility .............................................................. 37 


\section{TABLES}

1 Instruments and Observational Systems in Place at the Central, Boundary, and Auxiliary Facilities on October 31, 1994

2 Instruments and Observational Systems in Place at the Extended Facilities on October 31, 1994

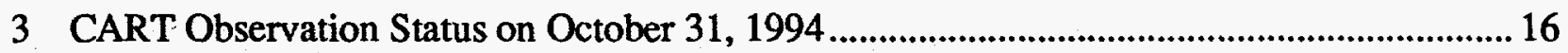

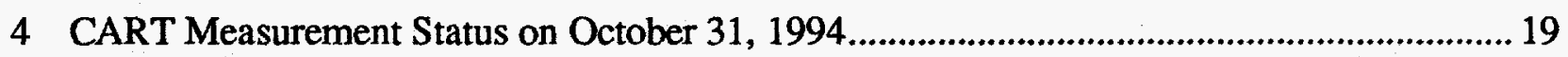

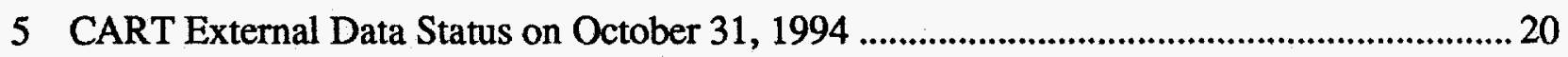

6 Observational Instruments and Systems Expected to Be in Place at Central and Boundary Facilities by October 31, 1995 ......................................................... 24

7 Observational Instruments and Systems Expected to Be in Place at Extended Facilities by June 30, 1995.

8 Status of Instrument Acquisition and Deployment on October 31, 1994 .............................. 30

9 Status of Radiometric Calibration Facility on October 31, 1994 …........................................... 35

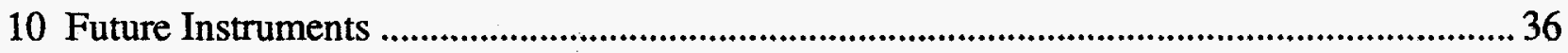

11 Radiosonde Launch Schedule: January 1-June 30, 1995 ........................................................... 40

12 CART Measurements Expected to Be in Place by June 30, 1995 ............................................ 41

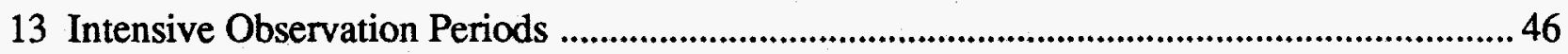

14 Collaborative Campaigns and Activities under Discussion ..................................................5

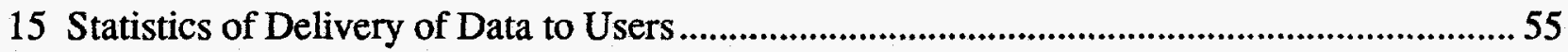




\section{ACKNOWLEDGMENTS}

This research was supported by the Atmospheric Radiation Measurement Program of the Atmospheric and Climate Research Division, Office of Health and Environmental Research, Office of Energy Research, U.S. Department of Energy, under contract PNL 144880-A-Q1 at the Cooperative Institute for Mesoscale Meteorological Studies, The University of Oklahoma (Schneider and Lamb), and under contract W-31-109-Eng-38 at Argonne National Laboratory (Sisterson). 


\section{NOTATION}

AERI atmospherically emitted radiance interferometer

ANL Argonne National Laboratory

ARL Air Resources Laboratory

ARM Atmospheric Radiation Measurement

AVHRR advanced very-high-resolution radiometer

BBSS balloon-borne sounding system

BSRN Broadband Solar Radiation Network

CART Cloud and Radiation Testbed

CASES Cooperative Atmosphere-Surface Exchange Site

CCN cloud condensation nuclei

CIMMS Cooperative Institute for Mesoscale Meteorological Studies

CSU

$\mathrm{CU}$

DA

DMT

Colorado State University

EBBR

EC

Colorado University

EFCOS

data assimilation

EML

EOP

Data Management Team

energy balance Bowen ratio

eddy correlation

ERL

EST

extended-facility code operations switch

Environmental Measurements Laboratory

experiment operations plan

ETL

Energy Research Laboratory

FDDA

Experiment Support Team

FTP

Environmental Technology Laboratory

GCIP

GCSS

four-dimensional data assimilation

GEWEX

GIST

GMS

GOES

GPS

GSFC

GVaP

$\mathrm{HD}$

File Transfer Protocol

GEWEX Continental-Scale International Project

GEWEX Cloud System Study

IDP

Global Energy and Water Cycle Experiment

GEWEX Integrated System Test

general measurement strategy

geostationary orbiting Earth satellite

global positioning system

Goddard Space Flight Center

GEWEX Water Vapor Project

hierarchical diagnosis

IOP

IR

Instrument Development Program

Intensive Observation Period

IRF

infrared

ISLSCP International Satellite Land-Surface Climatology Project

ISS

IT integrated sounding system

LBLRTM line-by-line radiative transfer model 


\section{NOTATION (Cont.)}

$\begin{array}{ll}\text { MFR } & \text { multifilter radiometer } \\ \text { MFRSR } & \text { multifilter rotating shadow-band radiometer } \\ \text { MPL } & \text { micropulse lidar } \\ \text { MSX } & \text { midcourse satellite experiment } \\ \text { MWR } & \text { microwave radiometer } \\ \text { NASA } & \text { National Aeronautics and Space Administration } \\ \text { NCAR } & \text { National Center for Atmospheric Research } \\ \text { NCSU } & \text { North Carolina State University } \\ \text { NIP } & \text { normal-incidence pyrheliometer } \\ \text { NIST } & \text { National Institute of Standards and Technology } \\ \text { NOAA } & \text { National Oceanic and Atmospheric Administration } \\ \text { NREL } & \text { National Renewable Energy Laboratory } \\ \text { NSSL } & \text { National Severe Storms Laboratory } \\ \text { NWS } & \text { National Weather Service } \\ \text { OU } & \text { University of Oklahoma } \\ \text { PARC } & \text { Palo Alto Research Center } \\ \text { PBL } & \text { planetary boundary layer } \\ \text { PNL } & \text { Pacific Northwest Laboratory } \\ \text { PSU } & \text { Pennsylvania State University } \\ \text { QME } & \text { quality measurement experiment } \\ \text { RASS } & \text { radio acoustic sounding system } \\ \text { SCM } & \text { single-column model } \\ \text { SDS } & \text { site data system } \\ \text { SGP } & \text { Southern Great Plains } \\ \text { SIROS } & \text { solar and infrared radiation observing system } \\ \text { SMOS } & \text { surface meteorological observation station } \\ \text { SNL } & \text { Sandia National Laboratories } \\ \text { SORTI } & \text { solar radiance transmission interferometer } \\ \text { SOW } & \text { statement of work } \\ \text { SST } & \text { Site Scientist Team } \\ \text { TOA } & \text { top of atmosphere } \\ \text { UAV } & \text { unmanned aerospace vehicle } \\ \text { UM } & \text { University of Massachussetts } \\ \text { UNAVCO } & \text { University NAVSTAR Consortium } \\ \text { USAF } & \text { U.S. Air Force } \\ \text { UTC } & \text { universal time coordinated } \\ \text { UU } & \text { University of Utah } \\ \text { UV } & \text { ultraviolet } \\ \text { UW } & \text { University of Wisconsin } \\ \text { VISSR } & \text { visible/IR spin-scan radiometer } \\ \text { VORTEX } & \text { Verification of the Origins of Rotation in Tornadoes Experiment } \\ \text { WPL } & \text { Wave Propagation Laboratory } \\ \text { WSI } & \text { whole-sky imager } \\ \text { WVMR } & \text { water vapor mixing ratio } \\ & \end{array}$


NOTATION (Cont.)

2-D

3-D

two-dimensional

three-dimensional 


\section{SITE SCIENTIFIC MISSION PLAN \\ FOR THE SOUTHERN GREAT PLAINS CART SITE \\ JANUARY-JUNE 1995}

\section{INTRODUCTION}

The Southern Great Plains (SGP) Cloud and Radiation Testbed (CART) site is designed to help satisfy the data needs of the Atmospheric Radiation Measurement (ARM) Program Science Team. This document defines the scientific priorities for site activities during the six months beginning on January 1, 1995, and also looks forward in lesser detail to subsequent six-month periods. The primary purpose of this Site Scientific Mission Plan is to provide guidance for the development of plans for site operations. It also provides information on current plans to the ARM functional teams (Management Team, Experiment Support Team [EST], Operations Team, Data Management Team [DMT], Instrument Team [IT], and Campaign Team) and serves to disseminate the plans more generally within the ARM Program and among the members of the Science Team. This document includes a description of the operational status of the site and the primary envisaged site activities, together with information concerning approved and proposed Intensive Observation Periods (IOPs). Amendments will be prepared and distributed whenever the content changes by more than $30 \%$ within a six-month period. The primary users of this document are the site operator, the site scientist, the Science Team through the ARM Program Science Director, the ARM Program Experiment Center, and the aforementioned ARM Program functional teams. This plan is a living document that will be updated and reissued every six months as the observational facilities are developed, tested, and augmented and as priorities are adjusted in response to developments in scientific planning and understanding. 


\section{PRIORITIES FOR SITE ACTIVITIES}

In descending order, we rank the priorities of site activities for January through June 1995 as follows:

1. Establish routine site operations.

2. Support all data quality assurance efforts, including implementation of quality measurement experiments (QMEs).

3. Plan and implement key IOPs.

4. Support the Instrument Development Program (IDP).

5. Plan and implement campaigns.

Within this ranking, the differences in relative importance between adjacent items are not large, but the top priority is clearly routine operations. The categorization is also somewhat artificial because many site activities are multipurpose; for example, IOP activities can simultaneously support Science Team, IDP, and campaign requirements. Even so, this ranking reflects our scientific assessment of the activities that should receive the most support during this period. The SGP site and the supporting structures within the ARM Program are still being consolidated. Progress to date has been significant, but substantial work remains to bring this facility and the data stream to full maturity. At the central facility, the aerosol and calibration trailers are close to implementation. In addition, a few instruments need to be installed, modified, or tested; and the site data system (SDS) has yet to become fully operational. The suite of boundary and extended facilities needs to be completed, and decisions must be made about the auxiliary facilities. Methods for developing scientifically sound and cost-effective plans for IOPs and campaigns are being developed and tested. Data quality assurance efforts are underway but are incomplete. The IOPs will focus on providing critical data sets on an episodic basis to the Science Team, as well as field support for instrument development and testing and for collaborative campaigns. Simply stated, the primary scientific goal for this period is the same as the goal for the last six months: translation of site implementation activities into routine data streams of known quality for as many parameters as possible. 


\section{SUMMARY OF SCIENTIFIC GOALS}

The primary goal of the SGP CART site activities is to produce data adequate to support significant research addressing the objectives of the ARM Program. These overall objectives, as paraphrased from the ARM Program Plan, 1990 (U.S. Department of Energy 1990), are the following:

- To describe the radiative energy flux profile of the clear and cloudy atmosphere

- To understand the processes determining the flux profile

- To parameterize the processes determining the flux profile for incorporation into general circulation models

To address these scientific issues, an empirical data set must be developed that includes observations of the evolution of the radiative state of the column of air over the central facility, as well as the processes that control that radiative state, in sufficient detail and quality to support the investigations proposed by the ARM Science Team. To address the entire $350-\mathrm{km} \times 400-\mathrm{km}$ SGP CART site, ARM relies on models to compute the process or properties that affect radiative transfer. This set of data includes measurements of radiative fluxes (solar and infrared [IR]) and the advective and surface fluxes of moisture, heat, and momentum occurring within the column and across its boundaries. Other entities to be described are cloud types, composition, and distribution (depth, fractional coverage, and layering); thermodynamic properties of the columnar air mass (temperature, pressure, and concentrations of all three phases of water); the state and characteristics of the underlying surface (the lower boundary condition); processes within the column that create or modify all of these characteristics (including precipitation, evaporation, and the generation of condensation nuclei); and radiatively significant particles, aerosols, and gases. Basic continuous observations must be made as often as is feasible within budgetary constraints. For limited periods of time, these observations will be supplemented by directed IOPs providing higher resolution or difficult-to-obtain in situ data.

Beyond simply providing the data streams, determining their character and quality as early as possible in the observational program is imperative. This evaluation will provide the basic operational understanding of the data necessary for an ongoing program of such scope. Although both reason and ample opportunity will exist to develop a further understanding of the ARM observations over the course of the program, the task of investigating and ensuring the data 
quality as soon as possible is important. In this regard, early and definitive QMEs would establish confidence in the measurements.

The SGP CART site is the first of several global locations chosen and instrumented for data collection. As summarized in a draft report by Sisterson and Barr, the scientific issues to be addressed by using data from a midlatitude continental CART observatory include the following:

- Radiative transfer in cloudless, partly cloudy, and overcast conditions

- Cloud formation, maintenance, and dissipation

- Nonradiative flux parameterizations

- The role of surface physical and vegetative properties in the column energy balance

- Other complications in the radiative balance in the atmosphere, particularly those due to aerosols, cloud condensation nuclei ( $\mathrm{CCN})$, and cloud-aerosol radiative interactions

- Feedback processes between different phenomena and different domains

The variety, density, and atmospheric volumetric coverage of the SGP instrumentation will be more comprehensive than that at any other ARM site; and the SGP site will experience a wider variety of atmospheric conditions than will any other ARM site. The resulting data would support a greater range and depth of scientific investigation than data from any other location, making it imperative for the ARM Program to develop and maintain a high-quality, continuous data stream from the SGP site.

In the process of distilling the measurements required by the proposals of the Science Team, the EST and the Science Director developed a set of general measurement strategies (GMSes), which represent groups of experiments requiring measurements with similar characteristics. The initial GMSes are designed to quantify the instantaneous radiative flux (IRF) and to support the requirements of the single-column model (SCM), data assimilation (DA), and hierarchical diagnosis (HD) research. The EST, IT, and others have established a set of critical measurements that has driven much of the SGP site development to date. The EST documented 
these measurements in 1992 and continues to work with the IT to prioritize the scheduling of instrument deployment. Because the site implementation has been phased, IRF measurements began first. They have been followed by the initiation of episodic measurements designed to support the SCM, DA, and HD experiments. This six-month period will include activities that will support a major portion of each of the GMSes.

Although budgetary limitations and delays in procurement have somewhat slowed the development and completion of the site, an ambitious schedule for implementation of an additional 13 extended facilities is underway. A fourth boundary facility was implemented last October for the fall SCM IOP. The emphasis in this six-month period will be on consolidating the existing suite of instruments and supporting systems and on resolving associated issues of data quality. Design reviews have been underway for new systems, including the calibration and aerosol facilities and the CART Raman lidar; these reviews address installation, operational, safety, and data quality issues. Preliminary and critical design reviews are anticipated for the CART millimeter cloud radar by late 1994 . Our ability to meet the long-term observational needs of the Science Team will depend on the continued development, acquisition, and deployment of instruments, as well as careful orchestration of IOPs and collaborative campaigns during the next few years.

The winter, spring, and early summer at the SGP site typically include a wide range of conditions-from cold, clear, and calm conditions interspersed with snow, blizzards, or ice storms; through organized convective activity producing significant precipitation and associated stratocumulus and cirrus decks; to high humidity, heat, and haze. In response to the sessions at the March 1994 Science Team meeting and subsequent GMS workshops and to surveys by the EST, site activities during the period of January through June 1995 will expand to include a wider suite of continuous and special measurements. Special operations will tentatively include four IOPs, two to support the SCM group, one to support the DA group, and one that is both an IRF and a collaborative campaign.

Budgetary constraints and the phased implementation of the Tropical Western Pacific CART site have forced the SGP CART site to reevaluate its ambitious radiosonde schedule (Cress 1994). Radiosondes are the single largest expense for the SGP CART site. A fourth boundary facility is required and was implemented at Purcell, Oklahoma, before the October 1994 SCM IOP. Although routine operations at the SGP CART site have not been reduced at the central facility since the previous six-month period, only one radiosonde is launched per day, instead of four, at the four boundary facilities. Furthermore, SCM IOPs have been reduced to 
three 3-week periods, instead of four. The SCM IOP in this period will be in April. The reduction in routine and IOP radiosondes has been implemented due to the increasing pressure of budgetary reductions. Revised schedules for IOPs and routine operations are implemented within 30 days of receiving official guidance for SGP CART site operations.

We will continue the suite of basic IRF observations above the central facility, including digital sky imagery, cloud base height observations, and hourly visual observations of sky conditions during operator hours. Routine radiosonde observations will include five daily balloon-borne sounding system (BBSS) launches on Monday through Friday (including holidays) at the central facility. One daily BBSS launch occurs on Monday through Friday (including holidays) at the four boundary facilities. Effort will continue to make fully operational the atmospherically emitted radiance interferometer (AERI), the solar radiance transmission interferometer (SORTI), the micropulse lidar (MPL), and vertical-profiling remote-sensing instrumentation. The interim whole-sky imaging system should be replaced by a day-night system in December 1994, and the solar and IR radiation observing system (SIROS) at the central facility will be completed with the installation of a new solar tracker and shading assembly; both of these improvements are important elements in the IRF measurements.

During this six-month period, we will also address more of the SCM, DA, and HD measurement needs with eddy correlation (EC) measurements at the central facility; with the 915- and 50-MHz profilers and the radio acoustic sounding system (RASS); with surface data collection from 13 more fully developed extended facilities, including seven with SIROS; and with continuous measurement of integrated liquid and cloud water plus frequent temperature, humidity, and wind profiles from the BBSSes at the four boundary facilities. Eddy correlation instrumentation is expected to be installed at several extended facilities in the late winter or early spring. The spring IOP to support the SCM research is tentatively scheduled for April 17 through May 7, 1995. The IOP will involve synchronized radiosonde launches from the central and four boundary facilities every three hours. Other IOPs relative to this period of time are discussed elsewhere (see Section 5).

Site operations will continue to support activities necessary for the IDP during IOPs, including the field adaptation of the AERI and SORTI and field testing of the SORTI, the ultraviolet spectral radiometer, and the MPL. Routine site operations of IDP instruments will be provided as budgetary constraints allow. Support will also be provided to several collaborating groups (see Section 5). 
In summary, our goal for this six-month period is to provide the Science Team with a suite of measurements that will support a wide range of research, while establishing solid procedures for instrument calibration and maintenance and continuing the series of QMEs. Data quality assurance efforts are central to the success of the entire program. 


\section{ESTABLISHMENT OF ROUTINE SITE OPERATIONS}

The ARM Program Plan, 1990 (U.S. Department of Energy 1990) states that the comparison of model results with observations will continue throughout the lifetime of the site. This approach is the primary rationale for the establishment of the decade-long routine operations at the SGP CART site. This strategy is mirrored in the experimental designs of the individual Science Team members. The experiment operations plans (EOPs) are a joint effort between the EST and Science Team members to implement the experimental designs of individual Science Team members. This site mission report collectively captures the data stream requirements of Science Team members. The EOPs are sorted into the four GMS categories. The locations and configurations of the various facilities within the SGP CART site, the instrumentation, the operation of the site, and budgetary considerations are optimized to meet the objectives of the GMS categories.

The overwhelming majority of the measurements with the highest priority, on which the existing experimental designs are based, are regular (i.e., routine) observations, as specified in the ARM Program Plan, 1990 (U.S. Department of Energy 1990). Scientifically and logistically, routine operations will serve as the basis and background for all nonroutine operations, including instrument development activities, IOPs, and collaborative campaigns directed toward obtaining difficult-to-gather or expensive in situ data. Consequently, development and validation of the basic observations retain top priority. Site development has progressed sufficiently to support several IOPs during this six-month period that do not require additional radiosonde launches, both to fill measurement needs unmet during routine operations and to support collaborative campaigns. The IOPs are an opportunity to provide more focused data sets to the Science Team and the scientific community at large.

The Site Scientist Team (SST) will work to ensure the scientific productivity of the site by providing guidance to the site operations manager and his staff on scientific matters related to the data stream, by answering questions from operations personnel concerning potential instrument problems, by reviewing schedules and procedures for instrument maintenance and calibrations, by reviewing designs for infrastructure supporting new instruments, by contributing to the design of the standard operating procedures, by reviewing and developing plans for special operations, and by helping to establish forecast support for routine and special operations. The SST, in cooperation with instrument mentors, will generally oversee the quality control effort at the CART site, a continuous activity that includes daily monitoring of the CART data streams in 
collaboration with the staff at the central facility and the development of a data quality assurance plan that will address the data originating at the SGP site.

The initial checks on data quality after instrument installation are provided by the instrument mentors; that is, after the mentors review the data streams to ensure that the acquired instrument is performing properly and that the data are accurately identified by the Experiment Center, the mentor approves a "beta" release. When the data quality is consistently acceptable and well documented, the mentor approves a "full" release of the data. Among the methods to document data quality, QMEs combine measurements from various instruments to evaluate the quality of individual data streams. The results of QMEs are documented and provide information about the "known and reasonable" quality of the data. These efforts are spearheaded by the instrument mentor, the EST, and the SST; however, suspect data can be reported to ARM by anyone via the Problem Review Board, which is made up of representatives from all of the ARM Program functional groups that meet weekly. The board's function is to review any problem associated with data and to assign appropriate personnel to resolve the problem.

During this six-month period, a high priority again will be comparison of similar data streams from different instrument packages, a natural and obvious complement to the efforts of the instrument mentors. A number of QMEs developed by instrument mentors, the SST, or the EST will be conducted by employing routine observations. Examples include comparison of (1) water vapor profiles retrieved from the microwave radiometer (MWR) with the BBSS moisture profile; (2) the brightness temperatures observed by the MWR with those values calculated by using the line-by-line radiative transfer model (LBLRTM) at the specific wave numbers at which the MWR operates; (3) cloud base heights derived from the Belfort ceilometer and MPL, with the cloud base heights derived from the whole-sky imager (WSI); (4) the observed to calculated broadband radiative surface fluxes; (5) virtual temperature and velocity profiles from the BBSS with data from the 915- and 50-MHz profilers; (6) temperature, humidity, and pressure measurements from the surface meteorological observation station (SMOS) with the $60-\mathrm{m}$ tower and the energy balance Bowen ratio (EBBR) system; and (7) momentum, heat, and moisture fluxes derived from the EBBR with those from EC systems. These studies will evaluate the vendor-specified operating ranges, precision, and accuracy of the CART instruments. 


\subsection{Routine Operations on September 30, 1994}

\subsubsection{Instruments and Observational Systems}

The accomplishments of the site development efforts are most evident at the central facility, with its functioning power and fiber-optic infrastructure and an array of instruments. Ten extended facilities (including the subset of instrumentation at the central facility) have at least a partial suite of instruments in place, and a fourth boundary facility has been functioning since the October 1994 IOP. Data transfer from the boundary facilities is currently by overnight express service to the central facility for data ingestion; however, T-1 lines are being planned for all boundary facilities for late winter or early spring. Figure 1 is a map of the SGP site, highlighting the locations of the developed extended and boundary facilities. The systems and instruments in place are summarized in Tables 1 and 2 . The auxiliary facilities, which are intended to be the base for the three-dimensional (3-D) observations of the cloud field over the central facility, will not be developed until plans for 3-D whole-sky imaging are more mature.

\subsubsection{Launch Schedule for BBSSes}

Until the full suite of remote-sensing systems is deployed to perform deep, detailed soundings of the wind, temperature, and moisture of the troposphere under a wide range of conditions, the BBSS will continue to be an expensive workhorse because of the cost of the expendables and manpower associated with an ambitious schedule of radiosonde launches. The number of BBSS launches sitewide should eventually be reduced to a minimum needed to support routine cross-checks on the remotely sensed measurements, but we are a number of years from that goal. In direct response to definitions of Science Team requirements (as summarized in Appendices A and B of Schneider et al. [1993] and reiterated at the March 1994 Science Team meeting), the frequency of routine launches at the central facility during this six-month period will be the same as in the previous six months. Routine operations will include five daily launches at the central facility; however, only one daily launch will occur at the four boundary facilities (see Section 4.2.6). The current launch times at the central facility were chosen to facilitate IRF and IDP research, and the launch times at the boundary facilities were chosen to support the MWR and nearby National Oceanic and Atmospheric Administration (NOAA) 404-MHz profilers with further RASS deployment and to complement and extend the wider network of National Weather Service (NWS) launches. 


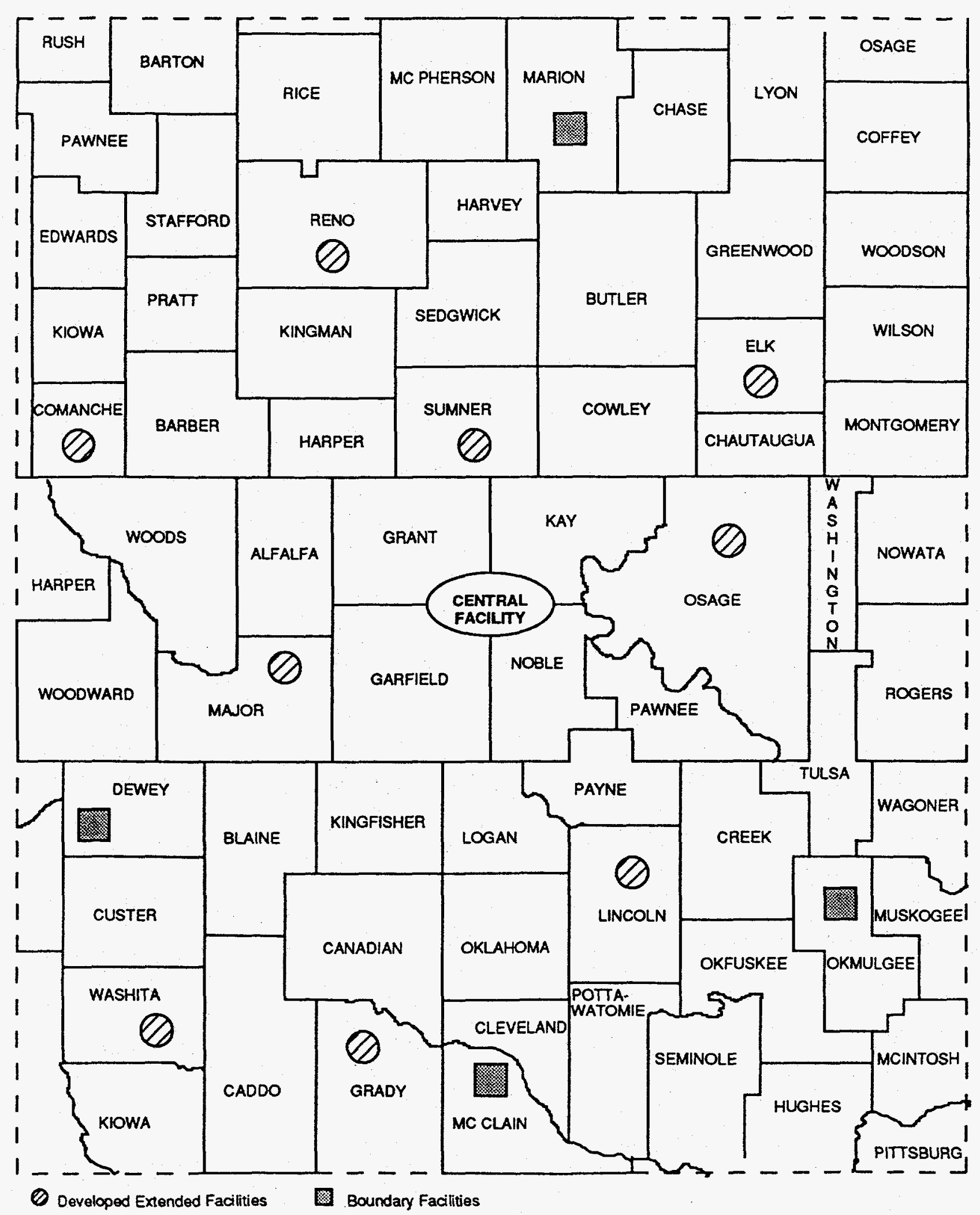

FIGURE 1 Overall View of the SGP CART Site 
TABLE 1 Instruments and Observational Systems in Place at the Central, Boundary, and Auxiliary Facilities on October 31, 1994

Central Facility

Radiometric Observations

AERI

SORTI (limited operations in test mode)

BSRN $^{\mathrm{a}}$

Pyranometer (ventilated)

Pyranometer (ventilated, shaded)

Pyrgeometer (ventilated, shaded)

NIP on tracker $^{b}$

MFRSR $^{\mathrm{c}}$

SIROS

Pyranometer (ventilated)

Pyrgeometer (ventilated, awaiting shading disk assembly)

NIP on tracker

MFRSR

Pyranometer (upwelling, above pasture at $10 \mathrm{~m}$ )

Pyrgeometer (upwelling, above pasture at $10 \mathrm{~m}$ )

MFR (upwelling, above pasture at $10 \mathrm{~m}$ )

Pyranometer (upwelling, above wheat at $25 \mathrm{~m}$ on $60-\mathrm{m}$ tower)

Pyrgeometer (upwelling, above wheat at $25 \mathrm{~m}$ on 60 -m tower)

MFR (upwelling, above wheat at $25 \mathrm{~m}$ on $60-\mathrm{m}$ tower)

Wind, Temperature, and Humidity Sounding Systems

BBSS

915-MHz profiler with RASS

$50-\mathrm{MHz}$ profiler with RASS

MWR

Heimann IR thermometer

Cloud Observations

WSI

Belfort laser (interim) ceilometer

MPL (IDP) ceilometer

Others

Temperature and humidity probes at $60 \mathrm{~m}$ on tower

Extended Facility Components

SIROS

Pyranometer (ventilated)

Pyrgeometer (ventilated, awaiting shading disk assembly)

NIP on tracker

MFRSR

Pyranometer (upwelling, at $10 \mathrm{~m}$ )

Pyrgeometer (upwelling, at $10 \mathrm{~m}$ )

EBBR

SMOS

Boundary Facilities

Limited implementation (fielding of BBSSes for IOPs and continuous operation of the MWR) near Hillsboro, Kans.; Vici, Okla.; and Morris, Okla.; BBSS

fielded at Purcell, Okla. 


\section{TABLE 1 (Cont.)}

\section{Auxiliary Facilities}

None in preparation

a BSRN, Broadband Solar Radiation Network.

b NIP, normal-incidence pyrheliometer.

${ }^{c}$ MFRSR, multifilter rotating shadow-band radiometer.

${ }^{\mathrm{d}}$ MFR, multifilter radiometer.

The two orbiting satellites (NOAA 11 and 12) both pass over the SGP CART site twice daily at times of low sun elevations, both in the morning (0630 and 0830, respectively) and evening (1830 and 2030, respectively, local time). Only half of the overpasses of both satellites have the highest elevation angles (smallest zenith angles) above $45^{\circ}$. Recently, NOAA 11 failed, and hence alternative data sources are being considered. The IRF Science Team members have agreed that launching radiosondes with satellite overpasses is not beneficial because of the low sun angles and low satellite elevations at the SGP CART site.

Four boundary facilities will launch radiosondes once per day at 1800 Greenwich mean time or noon local time. Boundary facilities will be staffed only during the period of 1030 to 1430 local time, Monday through Friday (including holidays). During IOPs, the boundary facilities will be staffed 24 hours per day for 21 consecutive days (including holidays).

The central facility will be staffed from 0530 to 2100 and from 2330 to 0330 local time, Monday through Friday (including holidays). During IOPs, the central facility will be staffed 24 hours per day, seven days per week (including holidays).

A fourth boundary launch site has been established in the vicinity of the Purcell, Oklahoma, NOAA profiler. Studies have shown a significant reduction in the uncertainties associated with divergence calculations based on radiosonde data results when four boundary facilities are used (Davies-Jones 1993; Mace et al. 1993; Michael 1994). Possible fifth and sixth boundary facilities are currently under consideration. 
TABLE 2 Instruments and Observational Systems in Place at the Extended Facilities on October 31, 1994a

\begin{tabular}{|c|c|c|c|c|c|}
\hline Location & SMOS & SIROS & EBBR & $\mathrm{EC}$ & Data Intake \\
\hline \multicolumn{6}{|l|}{ Kansas } \\
\hline $\begin{array}{l}\text { Hillsboro (boundary } \\
\text { facility) }\end{array}$ & - & * & * & - & Diskette \\
\hline Ashton & $\mathbf{X}$ & $\mathbf{X}$ & $\mathbf{X}$ & - & $\mathrm{EFCOS}^{\mathbf{b}}$ \\
\hline Coldwater & $\mathbf{X}$ & * & $\mathbf{X}$ & - & $\begin{array}{l}\text { EBBR by modem, } \\
\text { SMOS by diskette }\end{array}$ \\
\hline Plevna & $*$ & * & $\mathbf{X}$ & - & Modem \\
\hline Elk Falls & $*$ & * & $\mathrm{X}$ & - & Diskette \\
\hline Tyro & - & * & - & $*$ & $*$ \\
\hline Towanda & * & * & - & * & * \\
\hline Larned & $*$ & * & - & * & * \\
\hline LeRoy & * & * & - & * & * \\
\hline Hesston & $*$ & $*$ & - & * & $*$ \\
\hline \multicolumn{6}{|l|}{ Oklahoma } \\
\hline Lamont (central facility) & $\mathbf{X}$ & $\mathrm{X}$ & $\mathbf{X}$ & * & Direct connection \\
\hline Ringwood & $\mathrm{X}$ & $\mathrm{X}$ & $\mathrm{X}$ & - & EFCOS \\
\hline Meeker & $X$ & $*$ & $\mathrm{X}$ & - & $\begin{array}{l}\text { EBBR by modem, } \\
\text { SMOS by diskette }\end{array}$ \\
\hline Cordell & - & * & $\mathrm{X}$ & - & Modem \\
\hline El Reno & - & * & $*$ & - & $*$ \\
\hline Pawhuska & - & * & $\mathbf{x}$ & - & Diskette \\
\hline Vici (boundary facility) & - & * & - & $*$ & $*$ \\
\hline $\begin{array}{l}\text { Morris (boundary } \\
\text { facility) }\end{array}$ & - & * & $*$ & - & Diskette \\
\hline Ft. Cobb & - & * & - & * & * \\
\hline Cyril & * & * & - & * & * \\
\hline Byron & * & * & - & * & * \\
\hline Cement $^{c}$ & - & - & $\mathbf{X}$ & - & Modem \\
\hline $\begin{array}{l}\text { Purcell (boundary } \\
\text { facility) }\end{array}$ & - & $*$ & $*$ & - & Diskette \\
\hline
\end{tabular}

a The central facility includes the complement of instruments at an extended facility. These instruments are listed in Table 1 and are not repeated here. $X$, installed; *, planned for installation; -, no installation currently planned; "diskette," data are retrieved manually on diskette; "modem," data are retrieved remotely by telephone; and "EFCOS," data are retrieved automatically by computer through coded switches. All sites will eventually transfer data by coded switches to the central facility. Ten of the sites are colocated with either an Oklahoma Mesonet or an NWS site, so that a SMOS would be redundant and is not planned. Each site will have either an EBBR (over pasture) or an EC (over cropland) system.

b EFCOS, extended-facility code operations switch.

c Temporary facility to support the 1994 National Aeronautics and Space Administration (NASA) Global Energy and Water Cycle Experiment (GEWEX) studies. 


\subsubsection{Observations, Measurements, and External Data}

The observations being delivered to the Experiment Center from the SGP CART site as of October 31, 1994, are summarized in Table 3. The availability of data from a particular platform on any given day is a function of quality control, with some segments temporarily unavailable during evaluation or correction of problems. The other instruments operating at the site (Table 1) that are not in Table 3 either are still under evaluation by the instrument mentors or are awaiting the creation of the data intake modules necessary to add their data to the SGP data stream.

The measurements being produced at the Experiment Center as of October 31, 1994, for distribution to the Science Team are listed in Table 4. This summary includes both the measurements derived from the SGP CART site data and the data streams from sources external to ARM (e.g., the gridded data from the National Meteorological Center's ETA Model). Table 5 lists the external data that currently supplement the SGP site data.

\subsection{Site Development Activities}

\subsubsection{Facilities}

Most of the infrastructure at the central facility is complete, including the power, telephones, and fiber-optic data network. The three IDP pads were successfully completed in time to host the Remote Cloud Sensing IOP in April 1994 and are available to support visiting instruments.

A new design using electronic cooling is planned for the CART AERI, which is to be installed in late winter of 1995 . The current IDP AERI system requires liquid-nitrogen cooling, and the resulting impact on site operations has limited operation of the AERI. During the SCM IOPs, site operators hand-fill the AERI with liquid nitrogen at the beginning of each of three shifts.

The SORTI was installed in the optical trailer in December 1993 and is still undergoing testing. The Spinhirne MPL has been operating intermittently in the optical trailer and is also being adapted. The Belfort ceilometer, which is operating about $3 \mathrm{~m}$ east of the optical trailer, has proven to be relatively robust. The WSI is located about $15 \mathrm{~m}$ south of the optical trailer, at a location high enough so that the optical trailer does not interfere with the field of view. 


\section{Observation}

Platform

Comments

From the BBSS

Sonde temperature profile

Sonde relative humidity profile

Sonde pressure profile

Sonde wind speed profile

Sonde wind direction profile

Recalculation of research mode pressure, temperature, and humidity without ground check applied to data for the period $4 / 8 / 94$ to $5 / 20 / 94$

Recalculation of research mode pressure, temperature, and humidity with ground check applied to data for the period $4 / 8 / 94$ to $5 / 20 / 94$

Removal of ground checks from nominal pressure, temperature, and humidity variables for the period $5 / 21 / 94$ to $8 / 3 / 94$

From the MWR

Column-integrated precipitable water vapor

Column-integrated liquid water path

23.8-GHz brightness temperature

31.4-GHz brightness temperature

IR $(9.5-11.5 \mu \mathrm{m})$ sky temperature

From the AERI

Wave number $\left(520-1800 \mathrm{~cm}^{-1}\right)$

Mean IR radiance spectra ensemble

Standard deviation of spectra ensemble

Wave number $\left(1800-2725 \mathrm{~cm}^{-1}\right)$

Mean IR radiance spectra ensemble

Standard deviation of spectra ensemble

Mean IR radiance at 675-680, 700-705, $985-990,2295-2300,2282-2287$, and $2510-2515 \mathrm{~cm}^{-1}$

Standard deviation of the radiance at 675-680, 700-705, 985-990, 2295-2300, 2282-2287, and $2510-2515 \mathrm{~cm}^{-1}$

Brightness temperature at $675-680,700-705$, $985-990,2295-2300,2282-2287$, and $2510-2515 \mathrm{~cm}^{-1}$

From the EBBR (at 10 Sites)

Sensible heat flux to surface Latent heat flux to surface Net radiation flux to surface
sgpsondeC1.al

sgpsondeC1.al

sgpsondeC1.al

sgpsondeC1.al

sgpsondeC1.al

DsgpsondeptucalcC1.c1

DsgpsondeptucalcB 1.c1

DsgpsondeptucalcB4.c1

DsgpsondeptucalcB5.c1

DsgpsondenogcptucalcC1.c1

DsgpsondenogcptucalcB1.c1

DsgpsondenogcptucalcB4.c1

DsgpsondenogcptucalcB5.c1

DsgpsondenogcwrpnC1.c1

DsgpsondenogcwrpnB 1.cl

DsgpsondenogcwrpnB4.c1

DsgpsondenogcwrpnB5.c1

sgpmwrlosC1.al sgpmwrlosC1.al sgpmwrlosC1.al sgpmwrlosC1.al sgpmwrlosC1.al

sgpaerich1C1.al sgpaerich1C1.al sgpaerich1C1.al sgpaerich1C1.a1 sgpaerich1C1.al sgpaerich1C1.al sgpaerisummaryC1.al

sgpaerisummaryCl.al

Available

sgpaerisummaryC1.al

Available
Available $^{\mathrm{a}}$

Available

Available

Available

Available

Availableb

Available $^{b}$

Available ${ }^{b}$

Available $^{b}$

Available ${ }^{b}$

Available $^{b}$

Available $^{b}$

Available $^{b}$

Available $^{b}$

Available $^{b}$

Available $^{\mathrm{b}}$

Available $^{b}$
Available Available Available Available Available

Available Available Available Available Available Available Available

sgp30ebbrE4.al sgp30ebbrE4.al Available Available sgp30ebbrE4.al 
TABLE 3 (Cont.)

Observation

Platform

Comments

From the EBBR (at 10 Sites) (Cont.)

Soil heat flux to surface

Top and bottom temperatures

Top and bottom relative humidities

Top and bottom vapor pressures

Atmospheric pressure

Soil moistures at five points

Soil temperatures at five points

Scalar and resultant wind speeds

Mean and standard deviation of wind direction

From the SMOS (at Five Sites)

Mean and standard deviation of wind speed

Mean and standard deviation of wind direction

Vector-averaged wind speed

Mean and standard deviation of temperature

Mean and standard deviation of relative humidity

Vapor pressure

Mean and standard deviation of barometric pressure

Snow depth

Precipitation total

\section{From the BSRNC}

Direct beam-normal solar irradiance

Downwelling hemispheric diffuse solar irradiance

Downwelling hemispheric solar irradiance

Downwelling hemispheric IR irradiance

From the SIROS

Direct beam-normal solar irradiance

Downwelling diffuse solar irradiance

Downwelling hemispheric solar irradiance

Upwelling hemispheric solar irradiance

Upwelling hemispheric IR irradiance

Downwelling hemispheric IR irradiance

Hemispheric downward solar irradiance (415, $500,610,665,862$, and $940 \mathrm{~nm}$ )

Hemispheric downward total solar irradiance

Diffuse hemispheric downward solar irradiance $(415,500,610,665,862$, and $940 \mathrm{~nm})$

Diffuse hemispheric downward total solar irradiance

Direct beam-normal solar irradiance $(415,500$, $610,665,862$, and $940 \mathrm{~nm}$ )

Direct beam-normal total solar irradiance
sgp30ebbrE4.al

sgp30ebbrE4.al

sgp30ebbrE4.al

sgp30ebbrE4.al

sgp30ebbrE4.al

sgp30ebbrE4.al

sgp30ebbrE4.al

sgp30ebbrE4.al

sgp30ebbrE4.al

sgp30smosE4.al

sgp30smosE4.al

sgp30smosE4.al

sgp30smosE4.al

sgp30smosE4.al

sgp30smosE4.al

sgp30smosE4.al

sgp30smosE4.al

sgp30smosE4.al

sgpbsrnC1.a1

sgpbsrnC1.al

sgpbsrnC1.al

sgpbsrnC1.a1

sgpsirosC1.al

sgpsirosC1.al

sgpsirosC1.al

sgpsirosC1.al

sgpsirosC1.al

sgpsirosC1.al

sgpsirosC1.al

sgpsirosC1.al

sgpsirosC1.al

sgpsirosC1.al

sgpsirosC1.al

sgpsirosC1.al
Available

Available

Available

Available

Available

Available

Available

Available

Available

Available

Available

Available

Available

Available

Available

Available

Available

Available

Available

Available

Available

Available

Available $^{d}$

Available $^{d}$

Available $^{d}$

Available $^{d}$

Available $^{d}$

Available $^{d}$

Available $^{d}$

Available $^{d}$

Available $^{d}$

Available $^{\mathrm{d}}$

Available $^{d}$

Available $^{d}$ 
TABLE 3 (Cont.)

Observation

Platform

Comments

From the Belfort Ceilometer

Cloud base height

sgpblcC1.c1

Available

From the Profiling Radars

915-MHz wind speed profile 915-MHz wind direction profile

915-MHz virtual temperature profile

$50-\mathrm{MHz}$ wind speed profile

$50-\mathrm{MHz}$ wind direction profile

$50-\mathrm{MHz}$ virtual temperature profile

sgp915rwpwindC1.a2 sgp915rwpwindC1.a2

sgp915rwptempC1.a2

sgp50rwpwindCl.a2

sgp50rwpwindC1.a2

sgp50rwptempC1.a2

Available $^{d}$

Available $^{d}$

Availabled

Available $^{\mathrm{d}}$

Available $^{d}$

Available $^{d}$

Other systems

Interim WSI

$60-\mathrm{m}$ tower temperature and relative humidity

sgpwsicloudC1.c1

sgp30twr21x.C1

sgpltwr21x.C1

sgp1440twr21x.C1

Dsgpmfr10mC1.a1

Dsgpmfr25mCl.a1

Available $^{d}$

Available $^{\mathrm{d}}$

Upwelling MFR at $10 \mathrm{~m}$ (tower)

Upwelling MFR, precision solar pyranometer, and precision IR radiometer at $25 \mathrm{~m}$

From Future Instruments

Cloud base height (MPL)

sgpmplcbhC1.c1

Available $^{d}$

Available $^{\mathrm{d}}$

Ultraviolet spectral radiometer

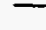

IDP testing

in $1994^{\text {? }}$

IDP testing

in 1995

a "Available" means that an instrument is in the field producing some level of data. Normally, the data have been fully released by the instrument mentor.

b Should be available in December 1994.

$\therefore$ BSRN, Broadband Solar Radiation Network.

d Beta release to select users.

e MFR, multifilter radiometer.

f May be available in late 1994. 
TABLE 4 CART Measurement Status on October 31, 1994

Measurement
Platform

Comments

From the BSRNa

Direct beam-normal solar irradiance

Calculated downward hemispheric diffuse solar irradiance

Downwelling hemispheric solar irradiance

Solar zenith angle used in calculation

From the $M W R$

Average (5-min) column-integrated water vapor Average (5-min) column-integrated liquid water Average (5-min) blackbody equivalent brightness temperature

Water vapor density profile

\section{From the MFRSR}

Optical depth $(415,500,610,665,862$, and

$$
940 \mathrm{~nm})
$$

Solar constant $(415,500,610,665,862$, and $940 \mathrm{~nm}$ )

Optical depth calculation standard error $(415,500,610,665,862$, and $940 \mathrm{~nm})$

\section{From Science Team Algorithms}

Reflected solar flux at top of atmosphere (TOA) (Cess algorithm)

Input for LBLRTM

Output from LBLRTM (IR spectral irradiance at $520-3020 \mathrm{~cm}^{-1}$ )

Difference of observations and calculations of IR irradiances

Map of wave number to physical process Statistical summary of radiance residuals Statistical summary of hourly AERI radiance
sgpbsrncalcC1.c1

sgpbsrncalcC1.c1

sgpbsrncalcC1.c1

sgpbsrncalcC1.c1

sgp5mwravgC1.c1 sgp5mwravgC1.c1 sgp5mwravgC1.c1

sgpmwrprofC1.c1

sgpsirosopdepthC1.c1

sgpsirosopdepthC1.c1

sgpsirosopdepthC1.c1

Available

Available

Available

Available for central facility
Availableb $^{b}$

Available

Available

Available
Available

Available

Available toa-refflx

lblrtm.input

lblrtm.output

qme-aerilbldiff

qme-MLSspecmap qme-aerilbl qme-aerimeans

\footnotetext{
a BSRN, Broadband Solar Radiation Network.
}

b Available means that an instrument is in the field producing some level of data; however, the data may not have been released by the instrument mentor or the Experiment Center and thus may not be available to the Science Team members.

c MFRSR, multifilter rotating shadow-band radiometer. 
TABLE 5 CART External Data Status on October 31, 1994

$\begin{array}{lll}\text { Measurement } & \text { Platform } & \text { Comments }\end{array}$

\section{From Satellites}

AVHRR channel 1 "albedo," channel 2

"albedo," channel 3 brightness temperature,

sgpavhrrX1.b1

Available b,c

channel 4 brightness temperature, channel 5 brightness temperature, satellite-solar azimuth angle, satellite zenith angle, and solar zenith angle ${ }^{a}$

AVHRR radiances: channel 3 calibrated radiances, channel 4 calibrated radiances, and channel 5 calibrated radiances

GOES radiances: channel 5 calibrated radiances, channel 8 calibrated radiances, and channel 12 calibrated radiances ${ }^{d}$

GOES visible: visible channel "albedo," satellite zenith angle, solar zenith angle, and satellite-solar azimuth angle

GOES IR: channel 5 IR brightness temperatures, channel 8 IR brightness temperatures, channel 12 IR brightness temperatures, satelite zenith angle, solar zenith angle, and satellite-solar azimuth angle

\section{From GOES Data}

GOES derived products: cloud amount (low, medium, and high), visible optical depth (low, medium, and high), IR optical depth (low, medium, and high), emissivity (low, medium, and high), cloud center height (low, medium, and high), cloud top height (low, medium, and high), cloud temperature (low, medium, and high), cloud thickness (low, medium, and high), reflectance (low, medium, and high), albedo (low, medium, and high), cloud center temperature (low, medium, and high), cloud top temperature (low, medium, and high), visible optical depth standard deviation (low, medium, and high), cloud center temperature standard deviation (low, medium, and high), broadband longwave flux (clear sky and total), narrowband IR flux (clear sky and total), broadband shortwave albedo (clear sky and total), narrowband visible albedo (clear sky and total), clear temperature, clear temperature standard deviation, narrowband visible albedo standard deviation, clear visible reflectance, and solar zenith angle 
TABLE 5 (Cont.)

\section{Measurement}

Platform

Comments

From the Forecast Systems Laboratory Maps Model

Gridded meteorological fields (eight daily) of height, temperature, relative humidity, and horizontal wind components, every $25 \mathrm{kPa}$ from the surface to $100 \mathrm{kPa}$, covering most of North America (subsets also available)

Gridded meteorological fields (eight daily) of height, temperature, relative humidity, and horizontal wind components, every $25 \mathrm{kPa}$ from the surface to $100 \mathrm{kPa}$, covering most of the SGP CART site

Derived variables from Mesoscale Analysis and Prediction System data similar to those in ngm250derived sgpallmaps $60 \times 1 . c 1$

Available

sgpmaps60X1.c1

Available

sgpmaps60derivX1.c1

Available

Gridded meteorological fields (four daily) of height, temperature, relative humidity, and sgpalleta90X1.c1

Availablec horizontal wind components, every $50 \mathrm{kPa}$ from the surface to $100 \mathrm{kPa}$, covering most of North America (subsets also available)

Gridded meteorological fields (four daily) of height, temperature, relative humidity, and horizontal wind components, every $50 \mathrm{kPa}$ from the surface to $100 \mathrm{kPa}$, covering most of the SGP CART site

Horizontally averaged values, derived from eta90 data, of surface pressure (reduced to sea level), tropopause pressure, and surface temperature

$S l a b$-averaged vertical profiles, derived from eta90 data, of temperature (T), $-\left(u^{*} d T / d x+v^{*} d T / d y\right)$, water vapor mixing ratio $(q),-\left(u^{*} d q / d x+\right.$ $\left.v^{*} d q / d y\right)$, horizontal wind components ( $u$ and $v$ ), $(d u / d x+d v / d y),-\left(u^{*} d u / d x+v^{*} d u / d y\right),-$ $\left(u^{*} d v / d x+v^{*} d v / d y\right)$, and geopotential height (Z), dZ/dx, dZ/dy, d2T/dx2, d2T/dy2, d2q/dx2, $\mathrm{d} 2 \mathrm{q} / \mathrm{dy} 2, \mathrm{~d} 2 \mathrm{u} / \mathrm{dx} 2, \mathrm{~d} 2 \mathrm{u} / \mathrm{dy} 2, \mathrm{~d} 2 \mathrm{v} / \mathrm{dx} 2, \mathrm{~d} 2 \mathrm{v} / \mathrm{dy} 2$

sgpeta90X1.c1

eta90derived

eta90derived

Available $^{c}$

\section{From the NOAA Wind Profiler Demonstration Network}

Profile of hourly consensus wind components Profile of hourly moments of wind components Profile of 6-min consensus wind components Hourly surface observations

\section{From the NWS}

Surface hourly observations Upper air observations
sgp60wpdnwndsX1.b1 sgp60wpdnmmtsX1.a1 sgp06wpdnwndsX1.b1 sgp60wpdnsurfX1.00

sgp60nwssurfX1.bl sgp60nwsswpaX1.b1
Available ${ }^{c}$

Available $^{c}$ Available $^{\mathfrak{c}}$

Available ${ }^{c}$ Available $^{c}$ 
TABLE 5 (Cont.)

Measurement

Platform

Comments

From the Kansas Surface Mesonetwork

Daily observations of maximum air temperature, minimum air temperature, total precipitation, sgpksudlymesoX1.b1

Available $^{\mathrm{f}}$

total solar radiation, maximum $5-\mathrm{cm}$ soil temperature, minimum $5-\mathrm{cm}$ soil temperature, maximum $10-\mathrm{cm}$ soil temperature, minimum 10-cm soil temperature, average relative humidity, maximum relative humidity, minimum relative humidity, mean wind speed, resultant wind speed, resultant direction, standard deviation of direction, and maximum (fastest minute) wind speed

From the Oklahoma Mesonetwork

Observations of air temperature, relative humidity, wind direction, wind speed, total solar radiance, total rainfall, and $5-$ and $10-\mathrm{cm}$ soil temperatures (15-min average)

Observations of air temperature, relative humidity, wind direction, wind speed, total solar radiance, total rainfall, and 5- and $10-\mathrm{cm}$ soil temperatures (5-min average)

$$
\text { sgp15okmX0.a0 }
$$

Available

sgp05okmX0.a0

Available

a AVHR, advanced very-high-resolution radiometer.

b Available means that an instrument is in the field producing some level of data; however, the data may have not been released by the instrument mentor or the Experiment Center and thus may not be available to the Science Team members.

c Data expected to become available during the fall of 1994.

d GOES, geostationary orbiting Earth satellite.

e Available January 1995.

f Four stations are available now in netCDF, and 10 other stations are available in ASCII code. All should be available in netCDF by January 1995.

Design requirements were reviewed (October 1993 and March, September, and November 1994) for the calibration platform deck and wiring of the calibration trailer, and final design requirements are currently under review. In addition, procedures are being developed to identify the number of sensors required, the required frequency of calibration for all radiometers at the SGP site, the frequency of sensor change-outs, and a method for tracking all sensors. The schedule for full operation of the calibration trailer appears to be July 1995. 
Plans for the aerosol intake stack and other structures in the aerosol trailer were reviewed in December 1993. Plans were mostly completed in April 1994, and nearly final drawings were received in July 1994. Final drawings are expected in December 1994. A statement of work (SOW) is currently being generated for procurement, and full operation of the facility is expected in June 1995. Instrumentation in the aerosol trailer will include an optical absorption system, two integrating nephelometers, an optical particle counter, a condensation particle counter, and an ozone monitor (see Table 6).

The SDS will continue to evolve during this six-month period. The initial plan for automated electronic data transfers (via telephone) from all boundary facility instruments was implemented during the January 1994 SCM IOP. Experience has shown that this configuration is insufficient to support the data transfer from the boundary facilities, so a different configuration is being planned and will need to be implemented and tested. During this time, each of the boundary facilities will have T-1 lines installed. The data from all instruments at boundary facilities will then be ingested locally (essentially via an Internet connection to the central facility). We expect the SDS to require several upgrades to support this critical expansion in capabilities. Further work is also needed to facilitate routine operations, particularly for assessment of instrument performance and data transfer, including a broader suite of data display capabilities. Once the SDS is near completion, procedures for system management and maintenance need to be written and transferred to site operations. Currently, data from the boundary facilities are being sent daily (Monday through Friday) to the central facility by an overnight transport service.

The ten current extended facilities (including one temporary non-ARM site in support of the Global Energy and Water Cycle Experiment [GEWEX] Continental-Scale International Project [GCIP], the GEWEX Cloud System Study [GCSS], and National Aeronautics and Space Administration [NASA] studies in the Little Washita watershed) will have been augmented with the installation of four more SIROSes (at Plevna and Elk Falls in Kansas and at Meeker and Cordell in Oklahoma) by late fall of 1994 or early winter of 1995 (Table 7). The temporary EBBR near Cement in Grady County, Oklahoma, will not be moved to the El Reno, Oklahoma, site until possibly August 1995, as requested, in support of the 1995 field activities in the Little Washita area. These and the remaining undeveloped extended facilities will require some or all of the following: installation of power and communications, construction of power and signal infrastructures, installation of automatic switches so that the SDS can interrogate extended facilities for data, and acquisition of suitably sized uninterruptible power supplies. The 
TABLE 6 Observational Instruments and Systems Expected to Be in Place at Central and Boundary Facilities by October 31, 1995

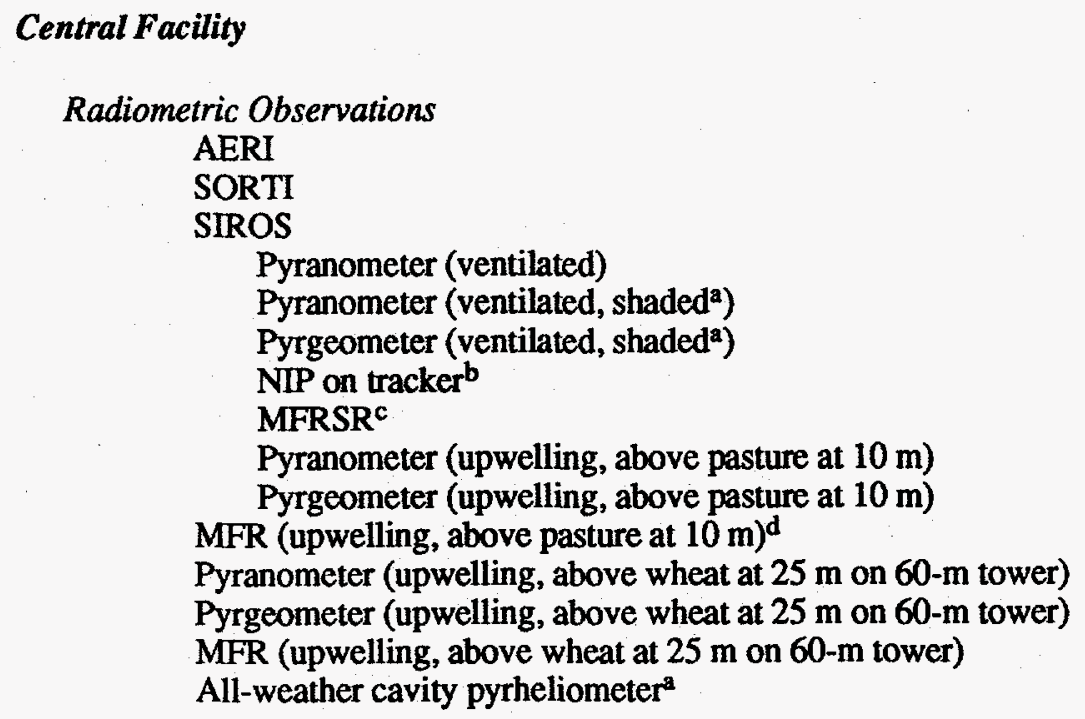

Wind, Temperature, and Humidity Sounding Systems

BBSS

915-MHz profiler with RASS

$50-\mathrm{MHz}$ profiler with RASS

MWR

Heimann IR thermometer

\section{Cloud Observations}

Day-night WSI ${ }^{2}$

Belfort laser (interim) ceilometer

MPL (IDP) ceilometer

Instruments and Systems in the Aerosol Trailer

Optical absorption system ${ }^{\mathrm{a}}$

Integrating nephelometer $(1 \lambda)^{a}$

Integrating nephelometer $(3 \lambda)^{2}$

Optical particle counter ${ }^{2}$

Condensation particle counter $r^{a}$

Ozone monitor ${ }^{2}$

Manifold sample system ${ }^{a}$

Instruments and Systems in the Calibration Trailer

Solar spectroradiometer ${ }^{\mathrm{a}}$

Site reference cavity radiometer ${ }^{\mathrm{a}}$

NIST standard lamps with controlled current source $e^{a, e}$

Optical breadboard system ${ }^{\mathrm{a}}$

Others

Temperature and humidity probes at $60 \mathrm{~m}$ on tower

EC systems near surface ${ }^{a}$

EC systems on $60-\mathrm{m}$ tower 
TABLE 6 (Cont.)

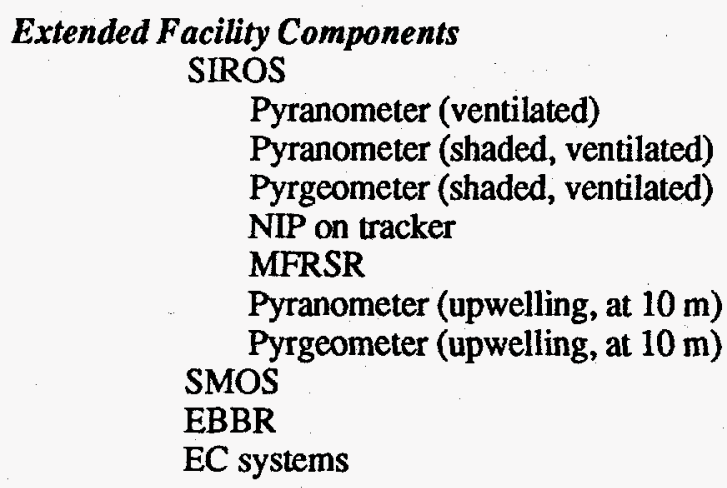

Boundary Facilities

Permanent installations ${ }^{2}$ are in place at Hillsboro, Kans.; Vici, Okla.; Morris, Okla.; and Purcell, Okla. Each of the first three sites includes a BBSS and an MWR; the fourth site consists of a BBSS.

Auxiliary Facilities

None in preparation

a Added after September 1994.

b NIP, normal-incidence pyrheliometer.

${ }^{c}$ MFRSR, multifilter rotating shadow-band radiometer.

d MFR, multifilter radiometer.

¿ NIST, National Institute of Standards and Technology.

development schedule calls for the completion of the infrastructure for 23 extended facilities by the end of June 1995; these facilities will be equipped as soon as the instrumentation is available.

The first three boundary facilities, which were temporarily installed in January 1994, initially supported a BBSS and an MWR close to the NOAA 404-MHz profilers. These initial boundary facilities were a minimal temporary arrangement sufficient to support the SCM IOPs. The NOAA sites include a set of surface instrumentation comparable to the SMOS suite, and these data accompany the profiler data, as external data. The schedule for installation of RASSes on the NOAA profilers is as follows: the Purcell, Oklahoma, system has been installed and is operational; the Haviland, Kansas, system has been installed but is not operational; the systems for Vici, Morris, and Lamont, Oklahoma, and for Hillsboro, Kansas, are scheduled for installation before the end of 1994; and the Neodesha, Kansas, system is scheduled for installation in early 1995 . 
TABLE 7 Observational Instruments and Systems Expected to Be in Place at Extended Facilities by June 30, 1995

\begin{tabular}{|c|c|c|c|c|c|}
\hline Location & SMOS & SIROS & EBBR & $\mathrm{EC}$ & Data Intake \\
\hline \multicolumn{6}{|l|}{ Kansas } \\
\hline $\begin{array}{l}\text { Hillsboro (boundary } \\
\text { facility) }^{\mathbf{b}}\end{array}$ & - & * & * & - & Direct connect to SDS \\
\hline Ashton & $\mathbf{X}$ & $\mathbf{X}$ & $\mathbf{X}$ & - & EFCOS $^{c}$ \\
\hline Coldwater & $X$ & $*$ & $\mathbf{X}$ & - & EFCOS \\
\hline Plevna & $\mathbf{X}$ & $\mathrm{x}$ & $\mathbf{X}$ & - & EFCOS \\
\hline Elk Falls & $\mathbf{X}$ & $\mathbf{X}$ & $\mathbf{X}$ & - & EFCOS \\
\hline Tyro ${ }^{b}$ & - & $*$ & - & * & * \\
\hline Towandab & $\mathbf{X}$ & $\mathbf{X}$ & $=$ & $\mathbf{x}$ & EFCOS \\
\hline Larned $^{b}$ & $\mathbf{X}$ & $\mathbf{X}$ & - & $X$ & EFCOS \\
\hline LeRoy $^{b}$ & $\mathbf{X}$ & $\mathrm{X}$ & - & $\mathbf{X}$ & EFCOS \\
\hline Hesston' & $\mathrm{X}$ & $\mathrm{X}$ & - & $\mathrm{x}$ & EFCOS \\
\hline \multicolumn{6}{|l|}{ Oklahoma } \\
\hline Lamont (central facility) & $\mathrm{X}$ & $\mathbf{x}$ & $\mathbf{X}$ & $\mathbf{x}$ & Direct connect to SDS \\
\hline Ringwood & $\mathrm{X}$ & $\mathrm{X}$ & $\mathrm{X}$ & $=$ & EFCOS \\
\hline Okmulgee & $\mathbf{X}$ & $\mathbf{X}$ & - & $\mathbf{X}$ & EFCOS \\
\hline Meeker & $\mathrm{X}$ & $\mathrm{X}$ & $\mathrm{X}$ & - & EFCOS \\
\hline Cordell & - & $\mathbf{X}$ & $\mathbf{X}$ & - & EFCOS \\
\hline El Reno ${ }^{b}$ & - & $*$ & $*$ & _- & * \\
\hline Pawhuska & - & $\mathbf{X}$ & $\mathbf{x}$ & - & EFCOS \\
\hline $\begin{array}{l}\text { Morris (boundary } \\
\text { facility }^{\text {b }}\end{array}$ & - & $*$ & $*$ & - & Direct connect to SDS \\
\hline $\begin{array}{l}\text { Vici (boundary } \\
\text { facility) }^{\mathbf{b}}\end{array}$ & - & * & - & * & Direct connect to SDS \\
\hline Ft. Cobb ${ }^{b}$ & - & * & - & * & * \\
\hline Cyril $^{b}$ & $\mathbf{X}$ & $\mathbf{X}$ & - & $\mathbf{X}$ & EFCOS \\
\hline Byron b & $X$ & $X$ & - & $\ddot{X}$ & EFCOS \\
\hline $\begin{array}{l}\text { Purcell (boundary } \\
\text { facility) }^{b}\end{array}$ & - & * & * & - & EFCOS \\
\hline
\end{tabular}

a The central facility includes the complement of instruments at an extended facility. These instruments are listed in Table 6 and are not repeated here. $X$, installed; ${ }^{*}$, planned for installation; -, no installation currently planned; and "EFCOS," data are retrieved automatically by computer through coded switches. All sites will eventually transfer data by coded switches to the central facility. Eight of the sites are colocated with either an Oklahoma Mesonet or an NWS site, so that a SMOS would be redundant and is not planned. Each site will have either an EBBR (over pasture) or an EC (over cropland) system.

b The boldface locations are those extended facilities expected to be installed by June 1995.

c EFCOS, extended-facility code operations switch. 
Experience during the January SCM IOP and subsequent directed tests led to the conclusion that the current boundary facilities are too close to the NOAA profilers, resulting in varying amounts of interference that produces data gaps in the high-altitude BBSS data. This problem led to specific questions about the Vaisala processing that sometimes excluded "good" data during specific conditions (e.g., nocturnal, low-level wind speed and direction profile data). Because the Vaisala system affords only a choice of unprocessed or processed data (not both), ARM had originally decided to take processed data; however, unanticipated problems make unprocessed data from the BBSS a requirement for at least some Science Team members. Hence, software was purchased in time for the spring 1994 IOP to allow unprocessed data to be collected from the BBSS at the three boundary facilities and also the central facility; however, on the basis of discussions at the Science Team meeting in early March 1994, processed temperature and humidity data but unprocessed wind data have been captured routinely after May 21, 1994. These changes allow both processed and unprocessed data to be collected and archived.

Although all new shipments of radiosondes since April 1994 have been factory-tuned to $401 \mathrm{MHz}$, potential interference by the NOAA profilers continued to be sufficient to cause the desire for colocation of boundary facility instrumentation with the profilers to be reconsidered. On the basis of a detailed examination of the problem of profiler interference (J. Schneider et al., unpublished information), all three boundary facilities were moved far enough away from the profilers (about one-half mile) to reduce considerably the interference problem. Boundary facilities remained operational in their original locations until the new boundary locations were prepared. The moves were completed before the October 1994 SCM IOP. The location of the fourth BBSS launch site (near Purcell, Oklahoma) was chosen to reduce any profiler-induced interference.

Recent discussions with some SCM Science Team members about the potentially large uncertainties associated with divergence calculations derived from radiosonde data for the SGP CART site indicate that uncertainty might be reduced significantly with four boundary facility locations, rather than the current three. Additional locations might further decrease uncertainty in calculations of divergence, but the costs might be prohibitive. Decisions will be made after the October 1994 SCM IOP about whether more than four boundary facility locations are required.

Figure 2 summarizes site development activities. Milestones and complex tasks are distinguished from simple tasks or activities. 


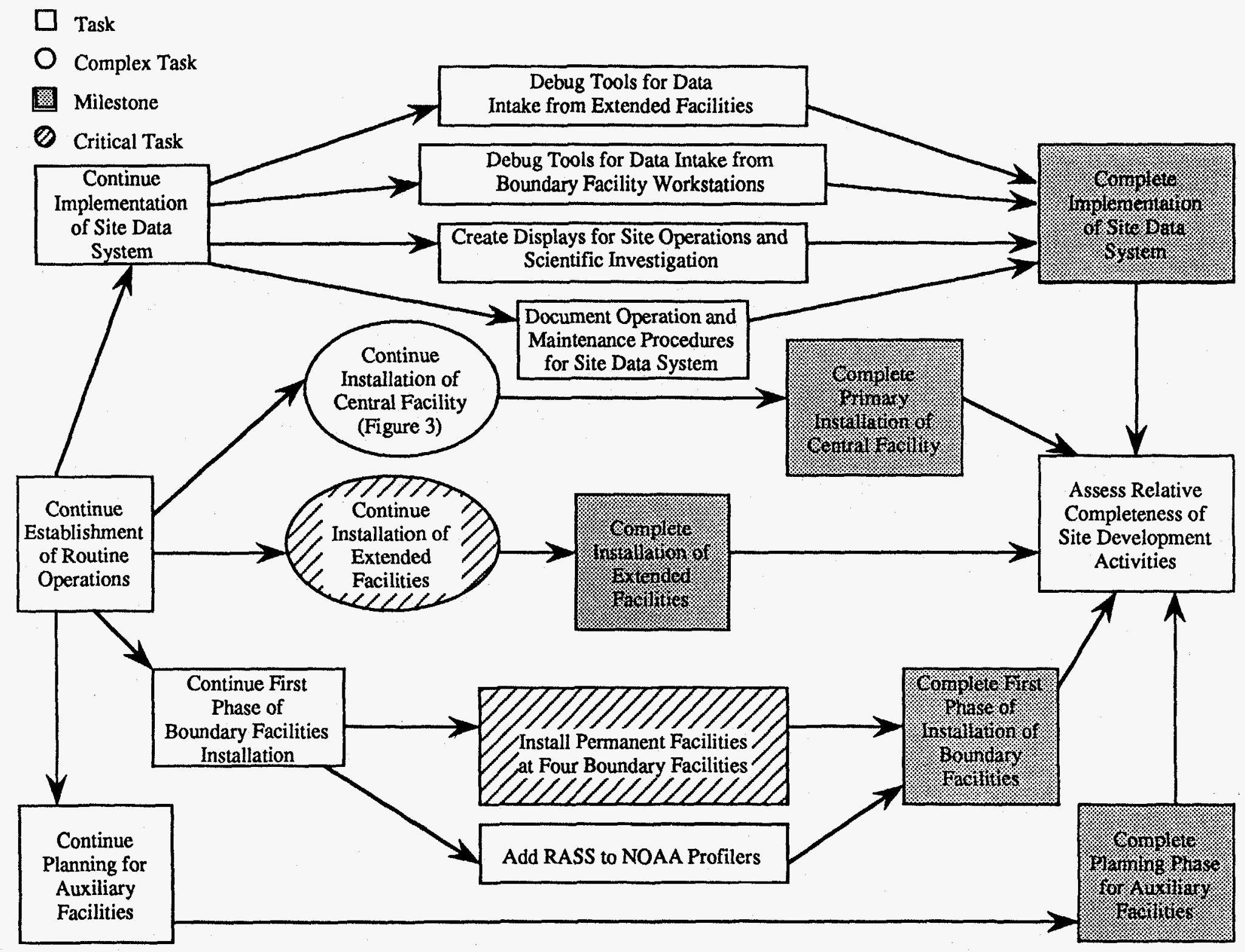

FIGURE 2 Site Development Activities to Establish Routine Operations 


\subsubsection{Instruments}

The current status of and plans for acquisition and deployment of instruments are summarized in Tables 8 through 10. During this six-month period, the central facility should gain the all-weather cavity pyrheliometer and most of the aerosol instrumentation, as indicated in Figure 3. Ozone sondes were originally included in the list of instruments planned for the SGP site, in anticipation of a need to correct measurements of radiation flux divergence on the basis of vertical ozone profiles. A recent analysis of SPECTRE data indicated that the error in flux divergence (with and without ozone profiles) was less than $2 \%$, a figure smaller than the model calculation errors. The requirement for ozone profiles has been reexamined. The installation cost is moderate $(\$ 20,000)$, but the individual ozone sondes are expensive ( $\$ 700$ per sonde), and manpower needs are intensive. A newly identified potential need for ozone profiles concerns the overlap of the ozone and water vapor absorption bands in the region of the AERI data around a wave number of 1150 . This overlap may require ozone profiles for analysis. This question has recently been evaluated by the Science Team and the EST. On the basis of all information, four to six ozone sondes per IOP have been requested. Launches are to be made during clear or nonovercast, high cloud conditions and near local noon and midnight. Currently, the differences in cost between a procurement of a service and procurement of a CART ozone sonde system are still being reviewed.

Of the 10 current extended facilities (including the central cluster at the central facility), the three with incomplete SIROS systems will be finished this fall, and another four sites will receive SIROS within this six-month period. During this six-month period, nine SMOS systems and six EC systems should be installed. If other SIROS and EC systems become available, the plan calls for the completion of a total of 16 extended facilities, as outlined in Table 7.

Atmospherically emitted radiation interferometers are planned for the Hillsboro, Vici, and Morris boundary facilities, but not necessarily for Purcell at the present time. The first available AERI will be installed at the Vici boundary facility.

When all of these instruments are in place (as summarized in Tables 6 and 7), the first phase of instrumentation at the central and boundary facilities will be complete, leaving only seven extended facilities, some boundary facility components, and the auxiliary facilities to be completed. 
TABLE 8 Status of Instrument Acquisition and Deployment on October 31, 1994

\begin{tabular}{|c|c|c|c|c|c|c|c|}
\hline Instrument & Mentor & Ordered & Delivered & $\begin{array}{l}\text { Central } \\
\text { Facility } \\
\text { Installation/ } \\
\text { Acceptance }\end{array}$ & $\begin{array}{l}\text { Extended } \\
\text { Facility } \\
\text { Installation/ } \\
\text { Acceptance }\end{array}$ & $\begin{array}{l}\text { Boundary } \\
\text { Facility } \\
\text { Installation/ } \\
\text { Acceptance }\end{array}$ & Comment \\
\hline WSI & Thome & $5 / 93$ & $12 / 94$ & $\begin{array}{l}\text { Loaner in } \\
10 / 20 / 93\end{array}$ & None planned & None planned & $\begin{array}{l}\text { Loaner data analysis to } \\
\text { be done off-site }\end{array}$ \\
\hline MWR & Liljegren & Done & $5 / 93$ & Done & None planned & Done & $\begin{array}{l}\text { Replaced central } \\
\text { facility unit with new } \\
\text { unit in } 11 / 93\end{array}$ \\
\hline IR thermometer & Liljegren & Done & Done & $11 / 93$ & None planned & $\begin{array}{l}\text { No IR } \\
\text { thermometers } \\
\text { at boundary } \\
\text { facilities }\end{array}$ & For use with the MWR \\
\hline BBSS & Lesht & Done & Done $(5 / 93)$ & Done & None planned & Done & $\begin{array}{l}\text { Interference by } \\
404-\mathrm{MHz} \text { profiler being } \\
\text { investigated }\end{array}$ \\
\hline EBBR & Cook & Done & $\begin{array}{l}10 \text { units; } 2 \text { more } \\
\text { in winter } 1994\end{array}$ & Done & 10 units installed & None planned & $\begin{array}{l}\text { Extended facilities to be } \\
\text { colocated with } \\
\text { boundary facilities }\end{array}$ \\
\hline 915-MHz RASS & Coulter & Done & Done & Done & None planned & None planned & $\begin{array}{l}\text { Transfer site data intake } \\
\text { to production system in } \\
11 / 94\end{array}$ \\
\hline 50-MHz RASS & Coulter & Done & Done & Done & None planned & None planned & \\
\hline SMOS & Hart & Done & Done & Done & $\begin{array}{l}5 \text { units in 4/93; } 5 \\
\text { in winter } 1994\end{array}$ & None planned & $\begin{array}{l}5 \text { units stored at central } \\
\text { facility; } 5 \text { more ordered } \\
1 / 93 ; \text { extended facilities } \\
\text { to be colocated with } \\
\text { boundary facilities }\end{array}$ \\
\hline
\end{tabular}


TABLE 8 (Cont.)

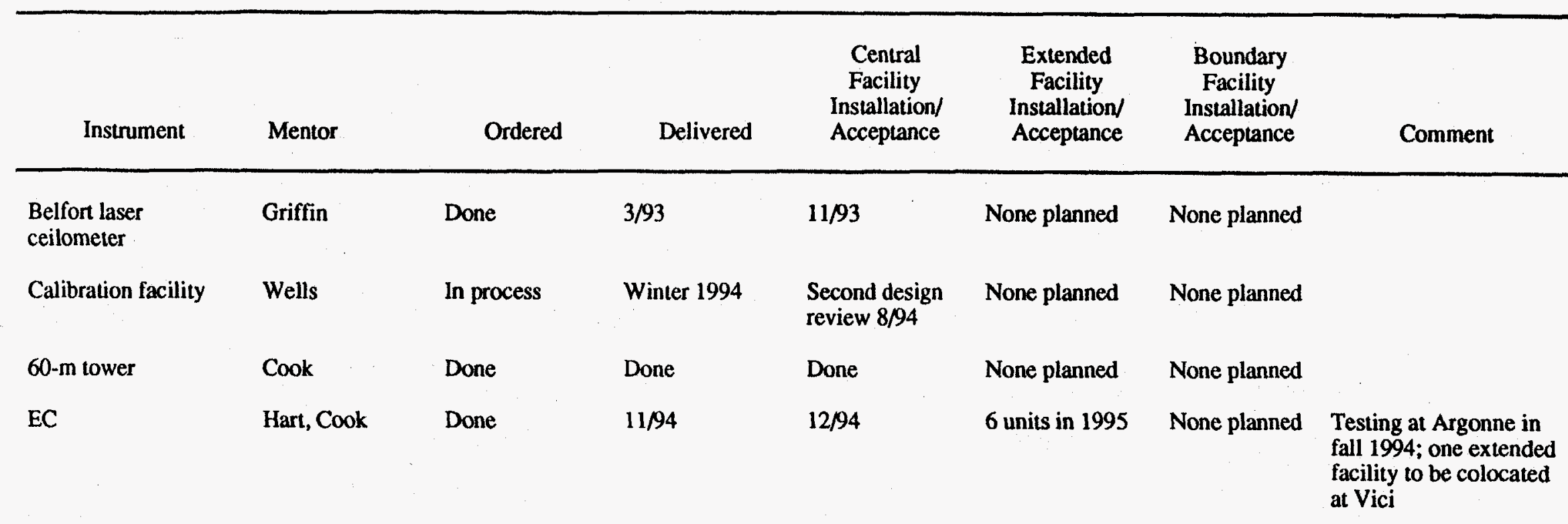

Aerosols

\begin{tabular}{|c|c|c|c|c|c|c|}
\hline $\mathrm{CCN}$ counter & Leifer & Canceled & & & None planned & None planned \\
\hline $\begin{array}{l}\text { Manifold sample } \\
\text { system }\end{array}$ & Leifer & Done & $\begin{array}{l}\text { Constructed at } \\
\text { EML }^{\mathrm{a}}\end{array}$ & $12 / 94$ & None planned & None planned \\
\hline Ozone monitor & Leifer & Done & At EML & $12 / 94$ & None planned & None planned \\
\hline $\begin{array}{l}\text { Filter collection } \\
\text { system }\end{array}$ & Leifer & Canceled & & & None planned & None planned \\
\hline $\begin{array}{l}\text { Optical absorption } \\
\text { system }\end{array}$ & Leifer & Done & At EML & $12 / 94$ & None planned & None planned \\
\hline $\begin{array}{l}3-\lambda \text { integrating } \\
\text { nephelometer }\end{array}$ & Leifer & Done & At EML & $12 / 94$ & None planned & None planned \\
\hline
\end{tabular}


TABLE 8 (Cont.)

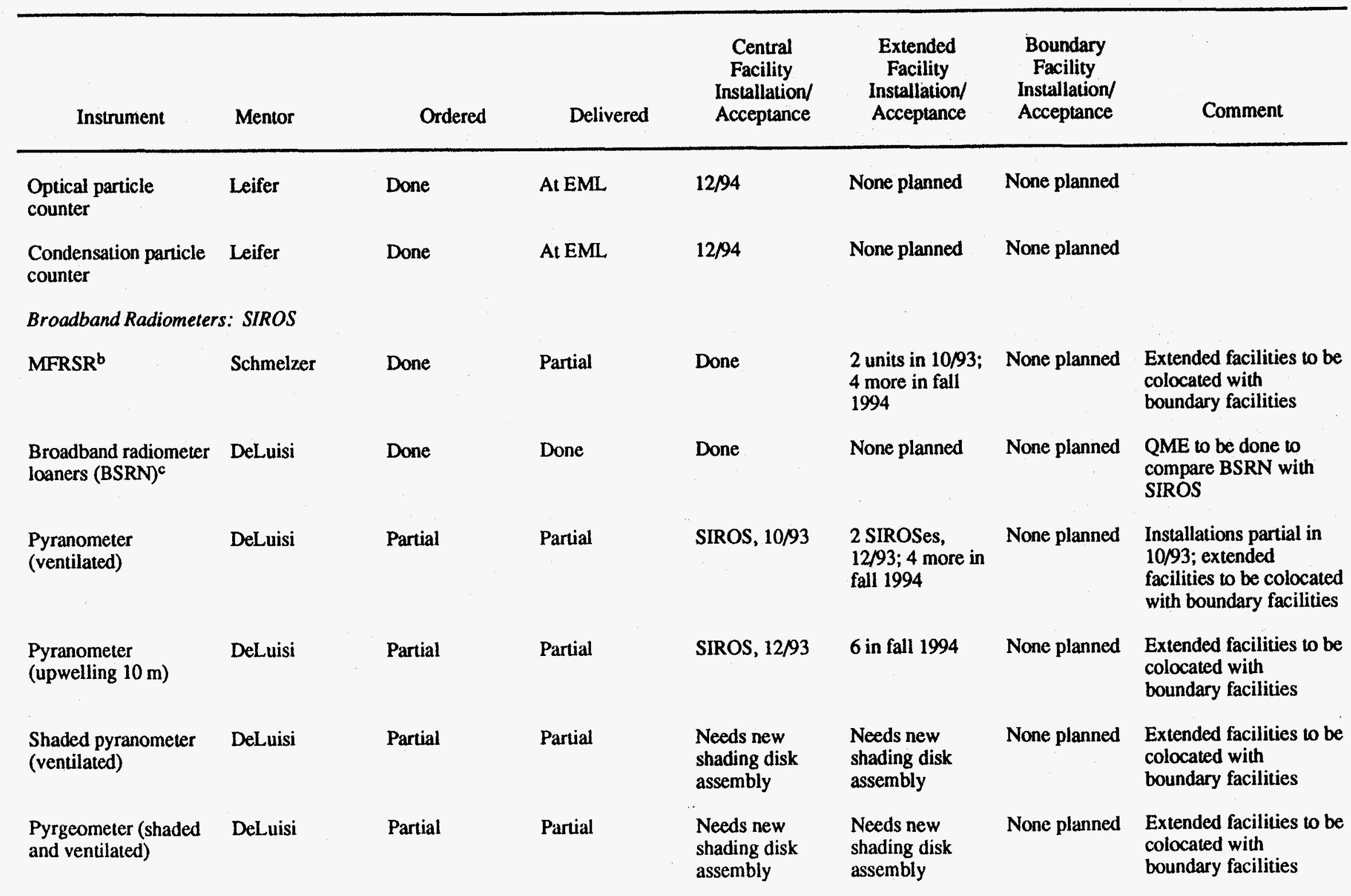


TABLE 8 (Cont.)

\begin{tabular}{|c|c|c|c|c|c|c|c|c|}
\hline Instrument & Mentor & Ordered & Delivered & $\begin{array}{c}\text { Central } \\
\text { Facility } \\
\text { Installation/ } \\
\text { Acceptance }\end{array}$ & $\begin{array}{l}\text { Extended } \\
\text { Facility } \\
\text { Installation/ } \\
\text { Acceptance }\end{array}$ & $\begin{array}{l}\text { Boundary } \\
\text { Facility } \\
\text { Installation/ } \\
\text { Acceptance }\end{array}$ & Comment & \\
\hline $\begin{array}{l}\text { Pyrgeometer } \\
\text { (upwelling } 10 \mathrm{~m} \text { ) }\end{array}$ & DeLuisi & Partial & Partial & SIROS, $12 / 93$ & 6 in fall 1994 & None planned & $\begin{array}{l}\text { Extended facilities to be } \\
\text { colocated with } \\
\text { boundary facilities }\end{array}$ & \\
\hline Pyrheliometers (NIP) ${ }^{d}$ & DeLuisi & Partial & Partial & SIROS, $10 / 93$ & $\begin{array}{l}2 \text { SIROSes, } \\
10 / 93 ; 4 \text { in fall } \\
1994\end{array}$ & None planned & $\begin{array}{l}\text { Will use new shading } \\
\text { and tracking assemblies }\end{array}$ & \\
\hline Trackers for NIP & DeLuisi & Partial & Partial & $\begin{array}{l}\text { Loaners from } \\
\text { ARLe initially }^{\text {en }}\end{array}$ & $\begin{array}{l}\text { Loaners from } \\
\text { ARL initially }\end{array}$ & None planned & $\begin{array}{l}\text { Extended facilities to be } \\
\text { colocated with } \\
\text { boundary facilities }\end{array}$ & \\
\hline $\begin{array}{l}\text { Tracking and shading } \\
\text { assemblies }\end{array}$ & DeLuisi & Partial & Fall 1994 & Fall 1994 & Fall 1994 & None planned & $\begin{array}{l}\text { Extended facilities to be } \\
\text { colocated with } \\
\text { boundary facilities }\end{array}$ & \\
\hline \multicolumn{9}{|c|}{ Other Radiometric Instruments } \\
\hline $\begin{array}{l}\text { All-weather cavity } \\
\text { pyrheliometer }\end{array}$ & DeLuisi & Done & Done & Winter 1994 & None planned & None planned & & \\
\hline $\begin{array}{l}\text { Pyranometer for } 60-\mathrm{m} \\
\text { tower }\end{array}$ & DeLuisi & Done & Done & $12 / 93$ & None planned & None planned & & \\
\hline $\begin{array}{l}\text { Pyrgeometer for } 60-\mathrm{m} \\
\text { tower }\end{array}$ & Deluisi & Done & Done & $12 / 93$ & None planned & None planned & & \\
\hline $\begin{array}{l}\text { Solar spectral } \\
\text { radiometer }\end{array}$ & Deluisi & $\begin{array}{l}\text { Specifications } \\
\text { being considered }\end{array}$ & Unknown & Unknown & None planned & None planned & & \\
\hline
\end{tabular}


TABLE 8 (Cont.)

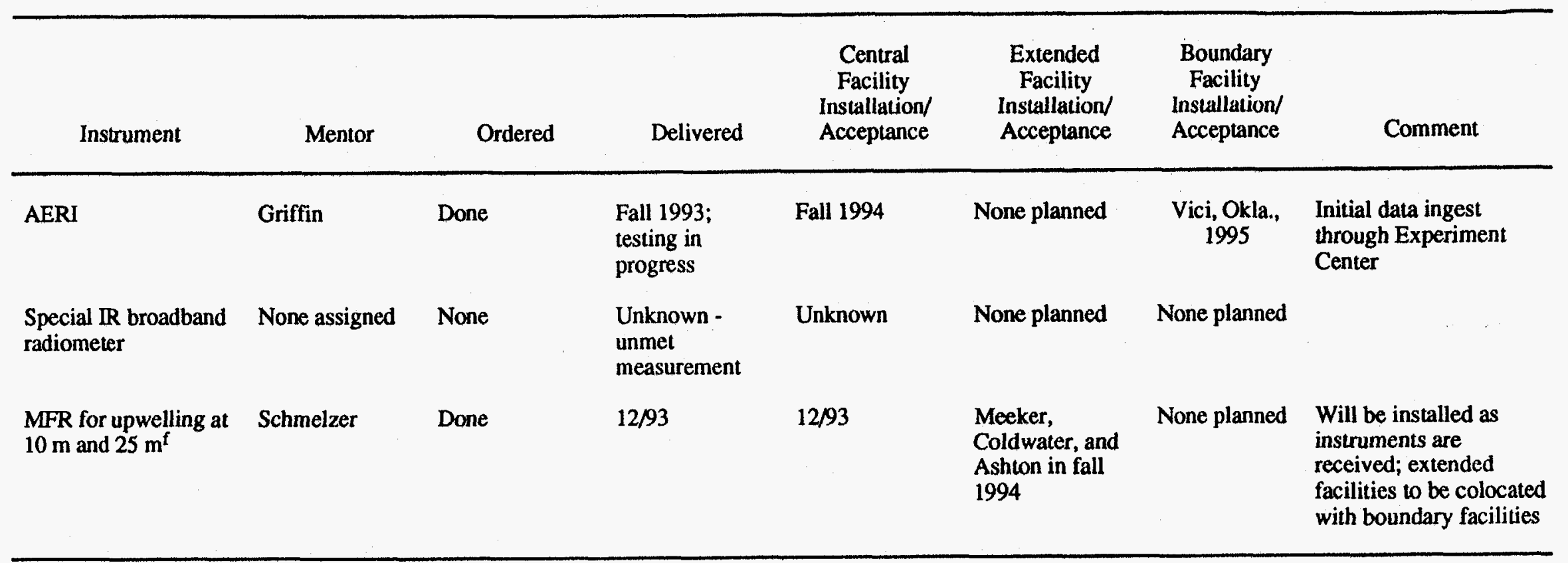

a EML, Environmental Measurements Laboratory.

b MFRSR, multifilter rotating shadow-band radiometer.

${ }^{c}$ BSRN, Broadband Solar Radiation Network.

d NIP, normal-incidence pyrheliometer.

e ARL, Air Resources Laboratory.

f MFR, multifilter radiometer. 
TABLE 9 Status of Radiometric Calibration Facility on October 31, 1994

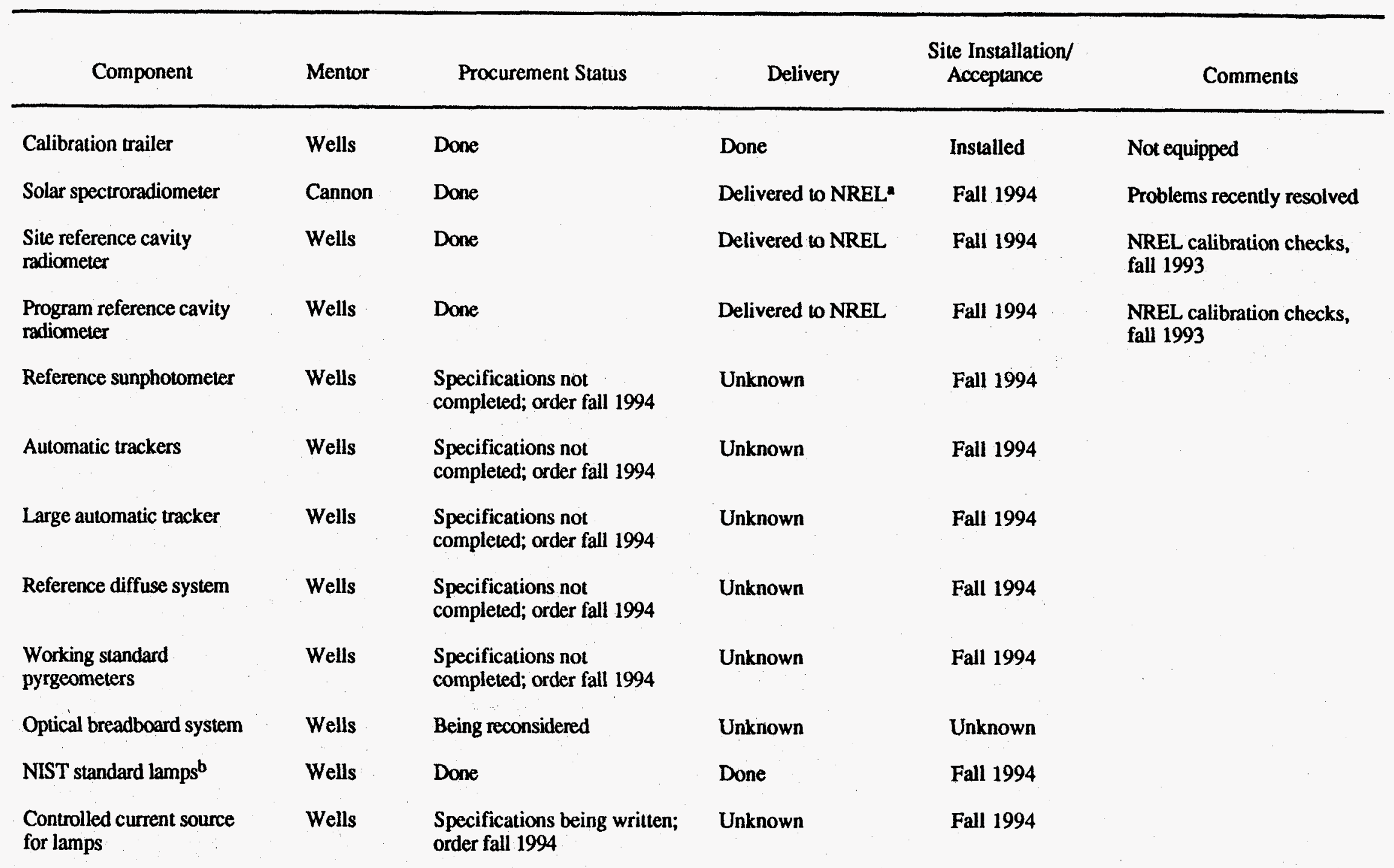


TABLE 9 (Cont.)

\begin{tabular}{|c|c|c|c|c|c|}
\hline Component & Mentor & Procurement Status & Delivery & $\begin{array}{l}\text { Site Installation/ } \\
\text { Acceptance }\end{array}$ & Comments \\
\hline Reference blackbody & Wells & $\begin{array}{l}\text { Specifications not } \\
\text { completed; order summer } \\
1994\end{array}$ & Unknown & Fall 1994 & Eppley standard blackbody \\
\hline
\end{tabular}

a NREL, National Renewable Energy Laboratory.

b NIST, National Institute of Standards and Technology.

TABLE 10 Future Instruments ${ }^{a}$

\begin{tabular}{llll}
\hline \multicolumn{1}{c}{ Future Instruments (IDP) } & IDP Investigator/Mentor & Procurement & IDP Testing \\
\hline Ultraviolet spectral radiometer & Harrison & No & Winter 1994 \\
Rotating shadow-band spectrometer & Michalsky and Harrison & No & Fall 1995 \\
SORTI & Murcray/Griffin & Summer 1994 & 1/94-present \\
Net radiometric profiler & Whiteman & No & Not scheduled yet \\
Raman lidar & Goldsmith/Griffin & SOW, late 1993 & Summer 1995 \\
Cloud radar & Widener & SOW, fall 1994 & Fall 1995 \\
Microwave water vapor profiler & Unknown & Unknown & Unknown \\
\hline
\end{tabular}

ancludes IDP instruments. 


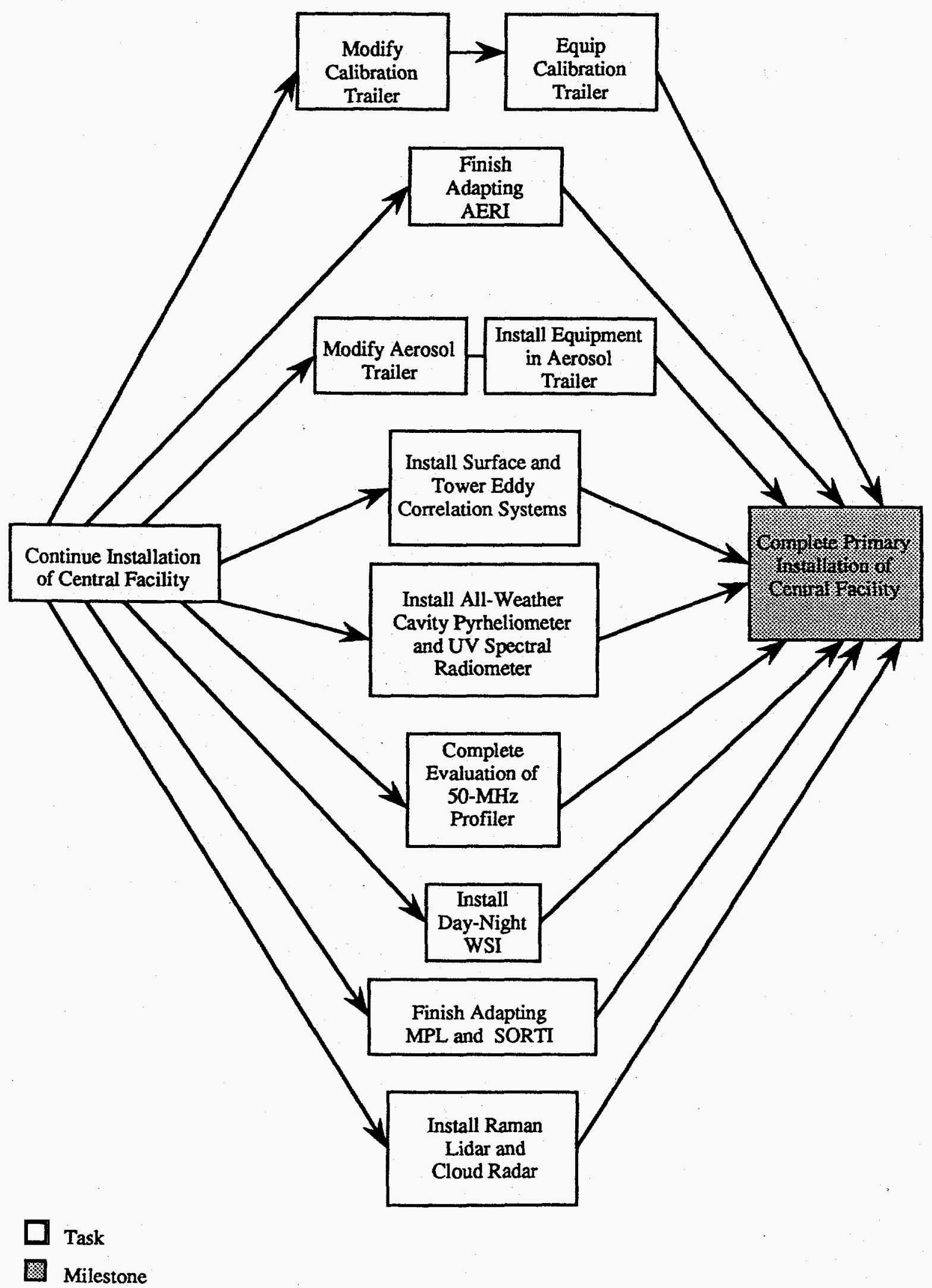

FIGURE 3 Site Development Activities to Install Central Facility 
Because of recent discussions with Science Team members involved in SCM boundary layer research, 915-MHz RASS systems are being considered at three or more locations within $75 \mathrm{~km}$ of the central facility to better represent boundary layer conditions within the SGP CART site. This addition, in concept, would add a new boundary layer facility to the CART site. Siting requirements and new locations will need to be established during this six-month period.

\subsubsection{Data Intake Modules for the Site Data System}

Several of the installed instruments and all of the new instruments will require creation of software to transfer the data from the instrument platforms to the SDS. Transfer of data by coded switches from the extended facilities will also be required. Because the telephone lines cannot support data transfer from the boundary facilities, $\mathrm{T}-1$ lines will be installed at these locations.

\subsubsection{Measurements and External Data}

The Experiment Center will continue to prepare software to produce measurements from the available observations. The status of the measurements near the beginning of this six-month period is summarized in Table 4.

\subsubsection{Limiting Factors}

The most basic of limiting factors is the amount of resources available for continuing site development, expanding operations, and providing necessary support for the IT, the DMT, and the EST. Shortfalls result in delays in implementation. Other significant limiting factors are the time lags inherent in the procurement process and the calibration of radiometers before installation.

All systems awaiting construction or installation go through a formal design review of structural and mechanical systems; for example, the aerosol intake stack for the aerosol trailer, the structure housing the CART Raman lidar, and the calibration platform deck have undergone such review. These reviews frequently identify deficiencies in plans and drawings related to engineering requirements, procurement details, safety, and quality control. This activity was recently expanded to include large or complex IOPs (e.g., the Cloud Remote Sensing IOP in April 1994) in an effort to integrate the staggering variety of IDP instrument support requirements for cost-effective and safe implementation. Neither construction nor installation will begin until the design review process has been successfully completed. 
The costs associated with BBSS launches (primarily expendables) will be a burden on the operations budget until these systems are replaced by continuous, unmanned remote-sensing systems. These expenses are a strong constraint on the total number and frequency of launches, making impossible the routine provision of all of the requested launches (eight per day at the central and boundary facilities) defined as the optimal sounding strategy for SCM requirements by the EST (M. Bradley and R. Cederwall, unpublished information). A proposed schedule for site operations that meets elements of both measurement strategies is outlined in Section 4.2.6.

Routine observations at boundary facilities will continue as outlined in the BBSS launch schedule outlined in Table 11. During the establishment of permanent boundary facilities, every effort will be made to minimize interruptions to that schedule. As mentioned earlier, remote sensing of virtual temperature profiles at all of the boundary facilities will probably not occur during this six-month period because NOAA has not yet installed the RASSes for all of its 404-MHz profilers.

\subsubsection{Schedule}

Changes in the schedule for site operations are driven primarily by the need to launch radiosondes. Site operations staff, the EST, and the Science Team have reached a compromise on the sonde launch schedule that remains the target goal for these six months. The new reduced schedule is shown in Table 11 and was implemented following the October 1994 SCM IOP. The establishment of a 24-hour-per-day, seven-day workweek at all facilities will be deferred until the resources are available.

For budget-planning purposes, the following schedule has been assumed. Routine radiosonde operations will be unchanged only at the central facility, but only one radiosonde will be launched per day at each of the four boundary facilities, Monday through Friday. Launch time at the boundary facilities is noon local time. The IOP operations will include three SCM IOPs of three weeks' duration each, with an additional one-week IOP that would be floated to support opportunities. For budget-planning purposes, IOPs have been carried out for October 24 through November 13, 1994, and have been proposed for April 17 through May 7, 1995; for July 17 through August 6, 1995; and for January 1996. Because of budgetary constraints, dates for IOPs will need to be established six months or more in advance to ensure efficient planning of activities that require accelerated radiosonde launch schedules. 
TABLE 11 Radiosonde Launch Schedule: January 1-June 30, 1995 (Times in UTC) $^{\text {a }}$

Central Facility Boundary Facilities

Routine Operations, January-April, Monday-Friday

0600

1200

1500

1800

1800

2100

SCM IOP, April-May, Monday-Sunday

0300

0300

0600

0600

0900

0900

1200

1200

1500

1500

1800

1800

2100

2100

2400

2400

Routine Operations, May-June, Monday-Friday

0600

1200

1500

1800

1800

2100

aTC, universal time coordinated. Launch time is 30 min earlier; the stated time represents the approximate midpoint of the flight.

4.3 Routine Operations and Measurements Expected to Be in Place by June 30, 1995

\subsubsection{Observational Instruments and Systems}

The suite of instruments expected to be installed by June 30,1995 , is summarized in Tables 6 and 7 .

\subsubsection{Measurements}

Table 12 provides a list of measurements, organized by type, derived from the SGP CART site and external data. 
TABLE 12 CART Measurements Expected to Be in Place by June 30, 1995

\section{Radiation}

Point AERI downwelling IR radiance

Point MFRSR global, diffuse, direct solar narrowband irradiance ${ }^{a}$

Point pyrgeometer downwelling global IR irradiance

Point pyrgeometer upwelling global IR irradiance

Point pyranometer downwelling global solar irradiance

Point pyranometer upwelling global solar irradiance

Central downwelling $10-\mu \mathrm{m}$ radiance

Reflected solar flux at top of atmosphere

Point IR (9.5-11.5 $\mu \mathrm{m})$ sky temperature

Satellite clear-sky reflectance

Satellite clear-sky-equivalent blackbody temperature

AVHRR radiances ${ }^{b}$

High-resolution IR radiation sounder radiances

VISSR atmospheric sounder radiances $c$

Site 2-D grid of surface downwelling solar radiative flux ${ }^{d}$

Site 2-D grid of surface upwelling solar radiative flux

Site 2-D grid of surface downwelling IR radiative flux

Site 2-D grid of surface upwelling IR radiative flux

Site average surface downwelling solar radiative flux

Site average surface upwelling solar radiative flux

Site average surface downwelling IR radiative flux

Site average surface upwelling IR radiative flux

\section{Temperature}

Central sonde vertical profile of temperature

Boundary sonde vertical profile of temperature

NWS sonde vertical profile of temperature

Extended 3-D grid of temperature

Site vertical profile of slab-averaged temperature

Site vertical profile of slab-averaged advective temperature tendency

\section{Pressure}

Central sonde vertical profile of pressure

NWS sonde vertical profile of pressure

Extended 3-D grid of pressure

Extended 3-D grid of pressure surface heights

Site vertical profile of sonde-derived pressure gradient

Site vertical profile of RASS-derived pressure gradient

\section{Water Vapor}

Central inferred vertical profile of water vapor density

Central sonde vertical profile of relative humidity

Central sonde vertical profile of WVMRe

NWS sonde vertical profile of relative humidity 
TABLE 12 (Cont.)

Water Vapor (Cont.)

Point MWR column-integrated "total precipitable" water vapor

Extended 3-D grid of WVMR

Site vertical profile of slab-averaged sonde WVMR

Site vertical profile of slab-averaged advective WVMR tendency

Winds and Dynamics

Central vertical profile of vertical wind components

Point sonde vertical profile of horizontal wind components

NWS sonde vertical profile of horizontal wind components

Extended 2-D grid of surface horizontal wind components

Extended 3-D grid of horizontal wind components

Site vertical profile of slab-averaged horizontal wind components

Site vertical profile of slab divergence of horizontal wind

Site vertical profile of slab-averaged advective momentum tendency

Site vertical profile of vertical velocity

Site vertical profile of geostrophic wind components

\section{Trace Gases}

Central surface ozone concentration

\section{Aerosols}

Central derived surface visibility

Central surface aerosol size distribution

Central surface aerosol absorption and scattering coefficient at $550 \mathrm{~nm}$

Central vertical profile of ceilometer relative aerosol backscatter

\section{Cloud Bulk Morphology and Distribution}

Central ceilometer cloud base height

Point satellite cloud top height

Central whole-sky image

Horizontal cloud distribution

Central fractional cloud cover

Cloud spacing

Cloud thickness

Site fractional cloud cover

Site cloud base height

Cloud top temperature (radiative)

Cloud base temperature (radiative)

NWS/USAF cloud fraction (by layer) ${ }^{f}$

NWS/USAF cloud type (by layer)

NWS/USAF cloud base (by layer)

Cloud base height 


\section{TABLE 12 (Cont.)}

\section{Cloud Microphysics and Precipitation}

Point MWR total cloud liquid water

Central vertical profile of phase of water

Point SMOS precipitation rate

Point NWS precipitation rate

Point Kansas Mesonet precipitation rate

Point Oklahoma Mesonet precipitation rate

Site 2-D grid of precipitation rate

Site total column cloud water

\section{Cloud Optical Properties}

Site satellite $2-\mathrm{D}$ grid of $1-\mathrm{km}$-scale cloud albedo

\section{Near-Surface Meteorology}

Point SMOS near-surface temperature

Point flux station near-surface temperature (two levels)

Point NWS near-surface temperature

Point Oklahoma Mesonet near-surface temperature

Point Kansas Mesonet near-surface temperature

Point SMOS near-surface pressure

Point flux station near-surface pressure

Point NWS near-surface pressure

Point Oklahoma Mesonet near-surface pressure

Point Kansas Mesonet near-surface pressure

Point SMOS near-surface relative humidity

Point flux station near-surface relative humidity

Point NWS near-surface relative humidity

Point Oklahoma Mesonet near-surface relative humidity

Point Kansas Mesonet near-surface relative humidity

Point SMOS near-surface horizontal wind components

Point flux station near-surface horizontal wind components

Point NWS near-surface horizontal wind components

Point Oklahoma Mesonet near-surface horizontal wind components

Point Kansas Mesonet near-surface horizontal wind components

Extended 2-D grid of near-surface temperature

Extended 2-D grid of near-surface pressure

Extended 2-D grid of near-surface WVMR

Site average near-surface temperature

Site average near-surface pressure

Site average near-surface WVMR

Site average near-surface horizontal wind components

Point-derived PBL depthg

Central capping inversion depth

Site average PBL depth 


\section{TABLE 12 (Cont.)}

\section{Surface Fluxes}

Point flux station surface sensible heat flux

Point flux station surface moisture flux

Point flux station surface momentum flux

EBBR surface net radiation flux

EBBR surface latent heat flux

EBBR ground heat flux

Site 2-D grid of surface sensible heat flux

Site 2-D grid of surface moisture flux

Site 2-D grid of surface momentum flux

Site average surface sensible heat flux

Site average surface moisture flux

Site average surface momentum flux

\section{Surface Properties}

Point-derived broadband surface albedo

EBBR soil moisture

Gridded surface conditions

Site 2-D grid of surface roughness

Site 2-D grid of surface albedo

Site average surface albedo

Site average surface roughness

Site ground surface type

Site average surface WVMR

Site average ground temperature

\section{Quality Measurements}

Comparison of observed and calculated IR irradiance

Comparison of observed and calculated microwave brightness temperatures

Comparison of MWR and sonde precipitable water

Comparison of EBBR and SIROS net radiation

a MFRSR, multifilter rotating shadow-band radiometer.

b AVHRR, advanced very-high-resolution radiometer.

c VISSR, visible/IR spin-scan radiometer.

d 2-D, two-dimensional.

e WVMR, water vapor mixing ratio.

${ }^{f}$ USAF, U.S. Air Force.

g PBL, planetary boundary layer. 


\section{INTENSIVE OPERATIONS}

The base of the ARM CART Program is a suite of continuous observations, but a number of critical observations are either too expensive to be produced continuously at the desired frequency or require instrumentation that cannot be deployed continuously. In addition, some questions concerning data accuracy or representativeness (for either established instruments or prototypes) can be answered only with periods of more frequent observations. Acquiring these observations will require special efforts and arrangements by the SGP site staff; such events are categorized as IOPs because they frequently include activities beyond the routine observations. The IOPs can be in support of the needs of the Science Team, QMEs, IDPs, campaigns, and even field tests of non-ARM instruments. Table 13 lists IOPs that have occurred, are occurring, or are in the design stage.

The initial design of most special operations will be in the hands of the EST. Prototype procedures to facilitate the design, review, and implementation processes are required for planning IOPs. Examples of such plans were included in Appendices A and B of Schneider et al. (1993). Similar documents are being prepared by the Campaign Team leader to facilitate interagency collaborations and by the Operations Team leader to facilitate use of guest instruments. The SST will assist the EST in the generation of plans for special operations; will include the plans for newly approved QMEs, IOPs, and campaigns in the Site Scientific Mission Plan; and will assist in the execution of special operations. With the many-month lead time necessary to schedule research aircraft, the design of special operations involving aircraft should begin more than one year before the projected operation and be sufficiently complete to be included in collaborative proposals.

\subsection{Quality Measurement Experiments}

As part of the data quality assurance effort, our focus needs to go far beyond the calibration of instruments- to intercomparison of data streams and to evaluations of our ability to capture an accurate representation of the state of the atmosphere. The QMEs are experiments that address these problems and are designed and managed in a manner analogous to the experimental designs of the Science Team members. While QMEs can be proposed by anyone 
TABLE 13 Intensive Observation Periods

\begin{tabular}{|c|c|c|c|c|c|}
\hline Date & Name & $\begin{array}{l}\text { Science Team } \\
\text { Member" }\end{array}$ & $\begin{array}{l}\text { EST } \\
\text { Contact }\end{array}$ & Description & Status \\
\hline $11 / 92$ & $\begin{array}{l}\text { Field Test of NCAR } \\
\text { Flux Profiler }\end{array}$ & D. Parsons (NCAR) & R. Cederwall & $\begin{array}{l}\text { Enhanced soundings at the central } \\
\text { facility and profiler site were made } \\
11 / 10-11 / 19 ; \text { boundary layer flights } \\
\text { were also conducted on a few days. }\end{array}$ & $\begin{array}{l}\text { Completed; data available } \\
\text { summer } 1993\end{array}$ \\
\hline $4 / 93$ & AERI Field Test & H. Revercomb (UW) & J. Liljegren & $\begin{array}{l}\text { Enhanced soundings at the central } \\
\text { facility were requested during the field } \\
\text { acceptance test of the AERI } \\
\text { instrument. }\end{array}$ & Completed 4/29/93 \\
\hline $\begin{array}{l}5 / 93 \\
6 / 93\end{array}$ & $\begin{array}{l}\text { Using the GPS for the } \\
\text { Measurement of } \\
\text { Atmospheric Water } \\
\text { Vapor }\end{array}$ & $\begin{array}{l}\text { Collaborative } \\
\text { (UNAVCO and NCSU) }\end{array}$ & J. Liljegren & $\begin{array}{l}\text { The purpose was to test the } \\
\text { investigators' technique for inferring } \\
\text { total precipitable water vapor in the } \\
\text { atmosphere column by using GPS } \\
\text { signals. }\end{array}$ & $\begin{array}{l}\text { Completed 6/8/93; data } \\
\text { available }\end{array}$ \\
\hline $6 / 93$ & $\begin{array}{l}\text { Warm-Season Data } \\
\text { Assimilation and ISS } \\
\text { Test }^{\mathrm{c}}\end{array}$ & D. Parsons (NCAR) & R. Cederwall & $\begin{array}{l}\text { This test was an enhanced sampling } \\
\text { (in time and space) of the SGP } \\
\text { domain for a 10-d period with profilers } \\
\text { and sondes. The primary goals of the } \\
\text { IOP were (1) to study the performance } \\
\text { of FDDA under thermodynamic } \\
\text { conditions typical of the continental } \\
\text { warm season and (2) to evaluate the } \\
\text { estimates of divergence and vorticity } \\
\text { from the prototype NCAR ISS with } \\
\text { interferometric techniques, the triangle } \\
\text { of three } 915-\mathrm{MHz} \text { profilers, and the } \\
\text { results of FDDA. }\end{array}$ & $\begin{array}{l}\text { Completed; all data } \\
\text { available at the } \\
\text { Experiment Center except } \\
\text { for FDDA, which will be } \\
\text { available upon request at } \\
\text { NCAR by the end of } 1994\end{array}$ \\
\hline $2 / 95$ & $\begin{array}{l}\text { MSX Satellite } \\
\text { Overflights }\end{array}$ & Collaborative & T. Cress & $\begin{array}{l}\text { Ground truth support for this satellite. } \\
\text { Nine sensors operate in the range of } \\
0.12-0.9 \mu \mathrm{m} \text { and a spectral IR } \\
\text { imaging telescope. }\end{array}$ & Under discussion \\
\hline
\end{tabular}


TABLE 13 (Cont.)

\begin{tabular}{|c|c|c|c|c|c|}
\hline Date & Name & $\begin{array}{l}\text { Science Team } \\
\text { Member }^{2}\end{array}$ & $\begin{array}{l}\text { EST } \\
\text { Contact }\end{array}$ & Description & Status \\
\hline $\begin{array}{l}\text { 2/95; } \\
5 / 95\end{array}$ & $\begin{array}{l}\text { Atmospheric Emission } \\
\text { Sounder Overflights }\end{array}$ & $\begin{array}{l}\text { S. Clough } \\
\text { (Atmospheric and } \\
\text { Environmental } \\
\text { Research, Inc.) }\end{array}$ & $\begin{array}{l}\text { M. } \\
\text { Laufersweiler }\end{array}$ & $\begin{array}{l}\text { Special ozone sonde launches will be } \\
\text { made to support these flights. }\end{array}$ & Planning underway \\
\hline $\begin{array}{l}3 / 95- \\
4 / 95\end{array}$ & $\begin{array}{l}\text { Surface Flux Responses } \\
\text { to Frontal Passages }\end{array}$ & $\begin{array}{l}\text { W. Blumen (University } \\
\text { of Colorado); L. Mahrt } \\
\text { (Oregon State } \\
\text { University) }\end{array}$ & R. Cederwall & $\begin{array}{l}\text { Document the changes in surface layer } \\
\text { fluxes in response to frontal passages. }\end{array}$ & Under discussion \\
\hline $\begin{array}{l}1 / 94 \\
4 / 94 ; \\
7 / 94 ; \\
10 / 94 \\
4 / 95\end{array}$ & Seasonal SCM IOP & D. Randall (CSU) & M. Leach & $\begin{array}{l}\text { Seasonal IOP with enhanced frequency } \\
\text { of observations, particularly vertical } \\
\text { soundings of temperature, water } \\
\text { vapor, and winds at central facility and } \\
\text { boundary facilities for periods of } 21 \mathrm{~d} \text {; } \\
\text { the required sounding frequency is } 8 / \mathrm{d} \text {. } \\
\text { The data are required for quantifying } \\
\text { boundary forcing and column } \\
\text { response. }\end{array}$ & $\begin{array}{l}\text { IOPs conducted in } \\
\text { January, April, and July; } \\
\text { planning in place for } \\
\text { October, with relocated } \\
\text { boundary facilities and the } \\
\text { addition of a fourth launch } \\
\text { site near the southern } \\
\text { border of the site }\end{array}$ \\
\hline $\begin{array}{l}4 / 95 \\
5 / 95\end{array}$ & $\begin{array}{l}\text { Simultaneous Ground- } \\
\text { Based, Airborne, and } \\
\text { Satellite-Borne } \\
\text { Microwave Radiometric } \\
\text { and In Situ Observations } \\
\text { of Cloud Optical } \\
\text { Properties and Surface } \\
\text { Emissivities }\end{array}$ & $\begin{array}{l}\text { W. Wiscombe (NASA- } \\
\text { GSFC); E. Westwater } \\
\text { (NOAA-ETL) }\end{array}$ & $\begin{array}{l}\text { M. } \\
\text { Laufersweiler }\end{array}$ & $\begin{array}{l}\text { Observations of cloud optical } \\
\text { properties will be obtained over the } \\
\text { CART site simultaneously from } \\
\text { ground-based, in situ, and satellite- } \\
\text { borne sensors; spatial variability of } \\
\text { surface emissivities will be assessed } \\
\text { to auempt retrieval of total } \\
\text { precipitable water and cloud liquid } \\
\text { water from the special sensor } \\
\text { microwave imager. }\end{array}$ & $\begin{array}{l}\text { Proposal distributed (to } \\
\text { IRF group contact); initial } \\
\text { planning discussions } \\
\text { between Wiscombe and L. } \\
\text { Fedor at NOAA; proposal } \\
\text { for } 45 \text { h of NOAA P-3 } \\
\text { flight time awarded to } \\
\text { Wiscombe and Schneider } \\
\text { in collaboration with } \\
\text { VORTEXf }\end{array}$ \\
\hline
\end{tabular}


TABLE 13 (Cont.)

\begin{tabular}{|c|c|c|c|c|c|}
\hline Date & Name & $\begin{array}{l}\text { Science Team } \\
\text { Member }^{\mathrm{a}}\end{array}$ & $\begin{array}{c}\text { EST } \\
\text { Contact }\end{array}$ & Description & Status \\
\hline $\begin{array}{l}4 / 94 \\
5 / 94 \\
4 / 95 \\
5 / 95\end{array}$ & $\begin{array}{l}\text { Remote Cloud Sensing } \\
\text { Field Evaluation }\end{array}$ & $\begin{array}{l}\text { R. McIntosh (UM); } \\
\text { B. Kropfli (NOAA); } \\
\text { T. Ackerman (PSU); } \\
\text { K. Sassen (UU); } \\
\text { A. Heymsfield } \\
\text { (NCAR); and others }\end{array}$ & $\begin{array}{l}\text { M. } \\
\text { Laufersweiler, } \\
\text { J. Griffin (IDP } \\
\text { contact) }\end{array}$ & $\begin{array}{l}\text { The primary purpose is the field } \\
\text { evaluation and calibration of several } \\
\text { remote-sensing cloud-observing } \\
\text { instruments (some of which are from } \\
\text { the IDP project). In situ cloud } \\
\text { observations are critical to the success } \\
\text { of this IOP. Enhanced soundings will } \\
\text { also be required at the central facility. }\end{array}$ & $\begin{array}{l}\text { IOP completed May 1, } \\
\text { 1994; data availability in } \\
\text { progress and summary } \\
\text { report in preparation; } \\
\text { planning underway for } \\
\text { another IDP effort in } 1995\end{array}$ \\
\hline $\begin{array}{l}4 / 95- \\
5 / 95\end{array}$ & VORTEX-ARM & $\begin{array}{l}\text { E. Westwater (NOAA- } \\
\text { WPL); W. Wiscombe } \\
\text { (NASA-GSFC); G. } \\
\text { Stephens and P. } \\
\text { Gabriel (CSU); J. } \\
\text { Schneider } \\
\text { (CIMMS/NSSL) }\end{array}$ & T. Cress & $\begin{array}{l}\text { Joint VORTEX/ARM proposal } \\
\text { approved for } 45 \text { h of P-3 aircraft time } \\
\text { to study stratocumulus clouds. } \\
\text { Coordination with Remote Cloud } \\
\text { Sensing IOP is being discussed. }\end{array}$ & Under discussion \\
\hline $\begin{array}{l}5 / 94 \\
1995 \text { dates } \\
\text { to be } \\
\text { determined }\end{array}$ & $\begin{array}{l}\text { WB-57 Overflight for } \\
\text { the Measurement of } \\
\text { Atmospheric Water } \\
\text { Vapor at High Altitude }\end{array}$ & $\begin{array}{l}\text { Collaborative } \\
\text { (Visidyne and Lockheed } \\
\text { PARC) }\end{array}$ & J. Liljegren & $\begin{array}{l}\text { The purpose was to attempt to infer } \\
\text { the vertical distribution of water vapor } \\
\text { at high altitudes from solar } \\
\text { transmission spectra. }\end{array}$ & $\begin{array}{l}\text { Completed; preliminary } \\
\text { transmission spectra } \\
\text { delivered to ARM; future } \\
\text { activities to be scheduled } \\
\text { as requested }\end{array}$ \\
\hline $5 / 94$ & VORTEX IOP & E. Rasmussen (NSSL) & T. Cress & $\begin{array}{l}\text { Special launches were made in support } \\
\text { of VORTEX, testing hypotheses of } \\
\text { the development and dissipation of } \\
\text { severe storms. }\end{array}$ & $\begin{array}{l}\text { IOP completed May } 31, \\
\text { 1994; data availability yet } \\
\text { to be determined }\end{array}$ \\
\hline
\end{tabular}


TABLE 13 (Cont.)

\begin{tabular}{|c|c|c|c|c|c|}
\hline Date & Name & $\begin{array}{l}\text { Science Team } \\
\text { Member }^{\mathbf{a}}\end{array}$ & $\begin{array}{c}\text { EST } \\
\text { Contact }\end{array}$ & Description & Status \\
\hline $\begin{array}{l}4 / 94 \\
5 / 95 \\
6 / 95\end{array}$ & $\begin{array}{l}\text { ARM UAV } \\
\text { Demonstration Flight } 2 \\
\text { (UDF-2) }\end{array}$ & $\begin{array}{l}\text { J. Vitko (SNL); } \\
\text { G. Stokes (PNL) }\end{array}$ & J. Liljegren & $\begin{array}{l}\text { Measurements of clear-sky flux } \\
\text { profiles acquired by a UAV and surface } \\
\text { support data are to be used to } \\
\text { understand clear-sky heating rates and } \\
\text { the ability of models to reproduce the } \\
\text { observations. }\end{array}$ & $\begin{array}{l}\text { First IOP conducted } \\
\text { successfully in April } \\
1994 \text {; planning underway } \\
\text { for spring } 1995\end{array}$ \\
\hline $8 / 94$ & $\begin{array}{l}\text { GEWEX/GCIP/GIST } \\
\text { IOPh }\end{array}$ & Collaborative & T. Cress & $\begin{array}{l}\text { Special launches were made in support } \\
\text { of the GCIP and GIST as part of an } \\
\text { effort to improve climate models by } \\
\text { improving parameterizations of } \\
\text { hydrologic and energy cycles. }\end{array}$ & $\begin{array}{l}\text { IOP successfully } \\
\text { conducted in August } 1994\end{array}$ \\
\hline $\begin{array}{l}9 / 94- \\
10 / 94 \\
6 / 95- \\
7 / 95\end{array}$ & $\begin{array}{l}\text { Sampling of Coherent } \\
\text { Structures with the } \\
\text { 915-MHz Profiler }\end{array}$ & R. Coulter (ANL) & R. Cederwall & $\begin{array}{l}\text { Fluctuations in the vertical wind and } \\
\text { index of refraction will be observed by } \\
\text { operating the } 915-\mathrm{MHz} \text { profiler with } \\
\text { RASS in a special mode during the } \\
\text { afternoon hours to sample convective } \\
\text { plume structures. }\end{array}$ & Scheduled \\
\hline \multicolumn{6}{|l|}{ Outlook } \\
\hline $\begin{array}{l}7 / 95- \\
8 / 95\end{array}$ & Summer PBL IOPi & $\begin{array}{l}\text { C. Doran (PNL); R. } \\
\text { Coulter (ANL); R. } \\
\text { Stull (UW); D. } \\
\text { Parsons (NCAR) }\end{array}$ & R. Cederwall & $\begin{array}{l}\text { Detailed observations of the } \\
\text { temperature and moisture profiles in } \\
\text { the PBL will be obtained within a } \\
\text { radius of } 75-125 \mathrm{~km} \text { of the central } \\
\text { facility by using airsondes, profilers, } \\
\text { and sodars to evaluate the variations of } \\
\text { the PBL structure in relation to } \\
\text { underlying surface fluxes. }\end{array}$ & Design in progress \\
\hline
\end{tabular}


TABLE 13 (Cont.)

\begin{tabular}{llcll}
\hline Date & Name & $\begin{array}{c}\text { Science Team } \\
\text { Memberd }\end{array}$ & $\begin{array}{c}\text { EST } \\
\text { Contact }\end{array}$ & Description \\
\hline Outlook (Cont.) & Collaborative & T. Cress & $\begin{array}{l}\text { Anamolous absorption of solar } \\
\text { radiation by clouds. The } \\
\text { phemomenon was first realized when } \\
\text { satellite measurements of solar } \\
\text { radiation absorbed by the surface } \\
\text { atmosphere were compared with solar } \\
\text { radiation measured at colocated surface } \\
\text { locations. }\end{array}$ \\
\hline
\end{tabular}

- Affiliations: ANL, Argonne National Laboratory; CIMMS, Cooperative Institute for Mesoscale Meteorological Studies; CSU, Colorado State University; ETL, Environmental Technology Laboratory; GSFC, Goddard Space Flight Center; NCAR, National Center for Atmospheric Research; NCSU, North Carolina State University; NSSL, National Severe Storms Laboratory; PARC, Palo Alto Research Center; PNL, Pacific Northwest Laboratory; PSU, Pennsylvania State University; SNL, Sandia National Laboratories; UM, University of Massachussetts; UNAVCO, University NAVSTAR Consortium; UU, University of Utah; UW, University of Wisconsin; and WPL, Wave Propagation Laboratory.

b GPS, global positioning system.

c ISS, integrated sounding system.

d FDDA, four-dimensional data assimilation.

e MSX, midcourse satellite experiment.

f VORTEX, Verification of the Origins of Rotation in Tornadoes Experiment.

B UAV, unmanned aerospace vehicle.

h GIST, GEWEX Integrated System Test.

i PBL, planetary boundary layer. 
within the ARM Program, they constitute a special joint responsibility for the EST and the SST. Not all QMEs require IOPs or increased data taking. The QMEs that are underway, in preparation, or under consideration include the following:

- Comparison of spectral radiances observed by the AERI and computed by the LBLRTM. This QME analyzes the residual differences and uses temperature and moisture profiles from the central facility as input. The goal is to improve the modeling of the surface spectral radiances.

- Comparison of cloud base observation data derived from the Scripps WSI, the Belfort ceilometer, the Spinhirne MPL, and any cloud radars deployed at the central facility for IOPs. This QME is under consideration; we are awaiting installations and IOPs including cloud radars.

- Comparison of broadband radiative surface fluxes, both between instruments measuring the same quantity and calculated from combinations of observations.

- Comparison of thermodynamic profiles derived from the BBSS and the RASS profilers with near-surface values from the SMOS and the 60-m tower instruments. This $\mathrm{QME}$ is under consideration.

- Comparison of wind profiles derived from the BBSS and the profilers. This $\mathrm{QME}$ is under consideration.

- Comparison of the fluxes derived from the EBBR and EC systems. This QME is under consideration; we are awaiting installation of the EC system at the central facility.

The results of these and other QMEs will have both short- and long-term effects on the ARM data stream and on site management, including advisories to the Science Team concerning data quality, modifications in strategies for data acquisition, and reassessments of measurement algorithms. The most important and unique of the instrument comparisons will be distributed as internal ARM reports and submitted for publication in appropriate journals. 


\subsection{Supplement to Continuous Observations}

During the various IOPs, maximizing the performance of key instrument systems at the site will be important, with priorities defined in the plans for each IOP. These essential systems should have any required preventive maintenance or calibrations performed before the start of these respective IOPs; furthermore, during the IOP, emergency repairs of these systems should take precedence over other site maintenance activities.

\subsection{Support for the Instrument Development Programs, Guest Instruments, and Campaigns}

The SGP CART site is an ideal location for rigorous field tests of new observational systems and has been designed to support these activities with a minimum of disruption to the continuous observations. The AERI is capable of routine detection of IR radiances with high spectral resolution and accuracy and will be essential to experiments on the effects of greenhouse gases, clouds, and fine particles on atmospheric transmission, absorption, and emission. More AERIs are scheduled for later deployment at the SGP boundary facilities, where the AERIs will be used to infer vertical profiles of temperature and humidity below the cloud base. The global positioning system (GPS) can be used to measure total water vapor in the atmosphere and was tested successfully at the SGP CART site. The GPS effort was not funded by ARM but was hosted by the site as a guest instrument. The SGP CART site is also a logistically friendly base for early tests of the ARM unmanned aerospace vehicle (UAV) (April 1994 and 1995), a platform that figures prominently in plans for future oceanic CART sites. The ARM UAV program is a self-standing sister program of ARM CART. The ARM UAV effort is a campaign that may occur in February 1995. The Remote Cloud Sensing IOP (April through May 1994) was a critical step toward building a capability to remotely and continuously observe both cloud distribution and microstructure (which are currently unfilled SGP observational needs).

\subsection{Campaign Planning}

Table 14 summarizes potential campaigns and cooperative projects that have been called to our attention. Plans for these activities are in various stages of development, and the topics are listed briefly here to generate further discussion. Inclusion in this list does not imply any endorsement of these activities by the ARM Program. 
Except for some special hydrologic measurements, the GEWEX/GCIP/GEWEX Integrated System Test (GIST) observations will be limited to currently operational observation networks and the SGP data. The GIST participants have expressed a strong interest in scheduling their fieldwork simultaneously with our spring and summer SCM IOPs.

TABLE 14 Collaborative Campaigns and Activities under Discussion

Title

Proponent/Contact ${ }^{\mathrm{a}}$

Projected Date

GEWEX

GCIP

P. Sellers

1995-1996

ISLSCPb

P. Sellers

1995-1996

GVaPc

H. Melfi

Spring 1996

GCSS

M. Moncrieff

To be determined

Soil Moisture and Temperature Profiling

J. Schneider (NSSL)

1995-1997

WB-57 Overflights

J. Liljegren

As requested

VORTEX ${ }^{d}$

E. Rasmussen (NSSL)

Spring 1995

Cooperative Multiscale Experiment

W. Cotton (CSU)

To be determined

CASES (boundary layer and hydrology facility) ${ }^{e}$

W. Blumen (CU)

Spring 1995

Gulf Moisture

W. Pennell

To be determined

MSX Satellitef

T. Cress

February 1995

affiliations: CSU, Colorado State University; CU, Colorado University; and NSSL, National Severe Storms Laboratory.

${ }^{b}$ ISLSCP, Intemational Satellite Land-Surface Climatology Project.

c GVaP, GEWEX Water Vapor Project.

d VORTEX, Verification of the Origins of Rotation in Tornadoes Experiments.

' CASES, Cooperative Atmosphere-Surface Exchange Site.

f MSX, midcourse satellite experiment. 


\section{DISTRIBUTION OF DATA}

As mentioned in Section 3, the EST is in the process of distilling the measurements required by the Science Team proposals in terms of the four GMS categories. In addition to that activity, the Experiment Center has begun to track data requests, particularly who has requested data and how many of the requests are being delivered in a weekly time period. This section of the Site Scientific Mission Plan attempts to integrate these two activities by grouping the users of the data into IRF, SCM, DA, HD, IDP, and miscellaneous categories. The IRF, SCM, DA, and HD catagories represent the GMS categories. The IDP category addresses IDP mentors who have requested data in support of their activities. The last category includes requests for data by the instrument mentors, as well as data requests by individuals either associated within the ARM infrastructure and outside of the ARM Program. Table 15 summarizes the particulars of the data being delivered to users for this time period. Table 15 reflects the EOP (from which the EST determines what data streams are required), the number of data platforms required by the EOP (data platforms include both observations and measurements obtained by an instrument with more than one sensor or providing more than one data stream, or by more than one instrument), the number of platforms the SGP CART site has or will have in the field, and a percentage that is based on the average of the weekly number of platforms and the number of platforms available being delivered from May 16, 1994, through November 27, 1994.

Table 15 is not complete. This table is based only on the information that had been officially logged and was available at the time of this report. Most of the data being requested are received from the SGP CART site or external data sources and are then repackaged for weekly distribution to the individual users. In some cases, the user can log into the Experiment Center and extract data (by anonymous File Transfer Protocol [FTP]). Tracking what the data user is actually receiving from the Experiment Center is more difficult. The information presented in Table 15 indicates that $58 \%$ of the IRF users, $53 \%$ of the SCM users, $73 \%$ of the DA users, $44 \%$ of the HD users, and $54 \%$ of the IDP users have been receiving some level of data for the period specified. The most significant improvement has been for the HD and IDP user catagories. Overall, $54 \%$ of the Science Team members are receiving some level of data, and $60 \%$ of the users over all categories are receiving data.

The information indicates that the IRF category has the largest number of users receiving data. This large number is because the central facility instrumentation addresses nearly all of the platform requirements of the IRF, and the central facility is nearly complete. More and more platforms will be available as boundary facilities are more fully developed and as the number of extended facilities increases. 


\begin{tabular}{|c|c|c|c|c|}
\hline & $\mathrm{EO}$ & Platforms & Platforms & $\begin{array}{l}\text { Average } \% \\
\text { of Available } \\
\text { Platforms } \\
\text { Delivered }\end{array}$ \\
\hline Data Users ${ }^{a}$ & Number & Required & Available & $5 / 16-11 / 27 / 94^{b}$ \\
\hline
\end{tabular}

\section{IRF Data Users}

Anderson
Byrne
Clough
Ellingson
Gautier
Harrison/Michalsky
Lacis/Del Genio
Landsfeld
Smith
Stamnes
Wang
Wiscombe

59

19

16

13

8

6

18

8

55

27

10

17

\section{SCM Data Users}

Baer

Kao

Randall

Somerville

DA Research Data Users

Ackerman/Albrecht (PSU) $\quad 58$

Bergstrom

Coulter

Doran

48

45

Kinne

Louis/Zivkovic

Mace (PSU)

Parsons (NCAR)

HD Research Data Users

Del Genio/Lacis

Lamb/Schneider

(CIMMS/OU)

Stensrud (CIMMS/OU)

Ramanathan
61

50

43

53
72

47

46

18

44

52

12

44

15

35

26

15

21

5
4

19

20

40

21

4

20

21

58

27

54
7

7

33

31
2

39
18

14

17

19.

17

3

17

17

51

25

49

4

33

27

1

36
32

63

64

69

61

Anonymous ${ }^{c}$

56

61

68

66

60

31

65

67

14

67 
TABLE 15 (Cont.)

\begin{tabular}{|c|c|c|c|c|}
\hline Data Users ${ }^{\mathbf{a}}$ & $\begin{array}{c}\text { EOP } \\
\text { Number }\end{array}$ & $\begin{array}{l}\text { Platforms } \\
\text { Required }\end{array}$ & $\begin{array}{l}\text { Platforms } \\
\text { Available }\end{array}$ & $\begin{array}{c}\text { Average } \% \\
\text { of Available } \\
\text { Platforms } \\
\text { Delivered, } \\
\text { 5/16-11/27/94b }\end{array}$ \\
\hline \multicolumn{5}{|l|}{ IDP Data Users } \\
\hline $\begin{array}{l}\text { Murcray } \\
\text { Revercomb } \\
\text { Scott } \\
\text { Spinhime } \\
\text { Westwater }\end{array}$ & $\begin{array}{l}68 \\
11 \\
63 \\
63 \\
30\end{array}$ & $\begin{array}{r}7 \\
25 \\
2 \\
2 \\
17\end{array}$ & $\begin{array}{r}6 \\
21 \\
1 \\
1 \\
12\end{array}$ & $\begin{array}{l}62 \\
72 \\
36 \\
54 \\
47\end{array}$ \\
\hline \multicolumn{5}{|c|}{ Miscellaneous Data Users } \\
\hline DeLuisi/Sandberg & 14 & 4 & 4 & Anonymous $c$ \\
\hline
\end{tabular}

a Affiliations of users: CIMMS, Cooperative Institute for Mesoscale Meteorological Studies; NCAR, National Center for Atmospheric Research; OU, University of Oklahoma; and PSU, Pennsylvania State University.

b These data percentages do not reflect data gathered from $6 / 19$ to 9/26.

c Data are obtained by the requester by anonymous FTP. The number of data platforms delivered is not known by the Experiment Center staff or the DMT. 


\section{LOOKING AHEAD}

As indicated in earlier sections, although budgetary limitations and delays in procurement have somewhat slowed the development and completion of the SGP CART site, a strong effort is now underway to achieve that site completion. Thus, by mid-1995, the site will be providing a significantly wider range of data streams, which, in turn, will support substantially enhanced EST algorithm development and Science Team research for and by all four GMS groups.

Two anticipated developments in the central facility are worthy of particular note in that regard. First, the expected enhancement by mid-1995 of some of the basic instrumentation there (e.g., day-night WSI, improved AERI, complete SIROS, and all-weather cavity pyrheliometer) will subsequently support a more complete specification of the radiative state of the near-surface atmosphere. This specification will be valuable to many IRF Science Team members, particularly if it is complemented by the development of a procedure to accurately measure the temperature and water vapor distributions in the lowest $200 \mathrm{~m}$ of the atmosphere. The development of the latter capability was strongly urged by the September 1994 IRF Workshop (University of Maryland). Second, the installation of the EC system at the central facility beginning in early 1995 (Section 4) will permit more complete characterization of the turbulent transfers of heat and moisture at the central facility. The EBBR fluxes currently determined at the central cluster are representative of the pasture at the central facility. The EC fluxes will be characteristic of the wheat at the central facility. Also, with the delivery of the portable EC system in early 1995 , the site will have the ability to compare flux measurements at the central and extended facilities against a single system.

By mid-1995, the development of procedures for the spatial integration of the turbulent and radiative fluxes will also be facilitated by the establishment of nearly all of the planned extended facilities (depending on procurement deliveries of instrumentation). Those extended facilities will all have recently calibrated EBBR systems, while six will also include SIROS units. In addition, the full establishment and operation of the fourth (southern) boundary facility by late 1994 should subsequently result in improved estimates of divergence and other derived parameters for the overall SGP CART site during 1995, as well as a better specification of the moisture flux across the southern boundary of that domain. These enhancements will particularly benefit the SCM and four-dimensional data assimilation groups.

Despite the previous substantial progress, the central facility will still lack several important observing systems and facilities by mid-1995. The planned installation of the Raman 
lidar in late 1995 is eagerly anticipated by the IRF Science Team members in particular. Such optimism stems from this state-of-the-science instrument having the potential to characterize the atmospheric state (e.g., water vapor, clouds, and aerosols) more accurately and with a finer vertical resolution than the existing suite of instruments (radiosondes and microwave radiometers) does. The aforementioned September 1994 IRF Workshop accordingly recommended that "the specification of the atmospheric state at the central facility be accomplished from the combined Raman lidar and RASS. The ARM Program must plan on a rapid implementation of these remote sensing technologies." The vigorous pursuit of this exciting opportunity would place the ARM Program at the international forefront in lessening the dependence of the atmospheric science community on the radiosonde for the thermodynamic profiling of the troposphere.

The central-facility observing systems and the facilities that will remain to be completed or installed after mid-1995 include the cloud radar and the aerosol and radiometric calibration trailers. These systems are in various stages of design review and development and will be deployed by July 1995. The data from the associated suite of aerosol instruments will fill a significant gap in the specification of the radiative state of the near-surface atmosphere. The establishment of the radiometric calibration facility is a key element in the total quality control effort for the wide variety of radiometers at the central facility. The cloud radar will be equipped to map the vertical extent of cloud boundaries up to a height of approximately $20 \mathrm{~km}$.

Measurements of vertical wind speed will be made by Doppler analysis. The system will operate only in the vertical pointing position.

During the second half of 1995 and all of 1996, the SGP CART observational capabilities will likely be further enhanced as a result of ongoing interactions between ARM and several other federally funded research programs having an interest in the SGP. To date, these interactions particularly involve the GCIP component of GEWEX and have already resulted in the formation and functioning of a joint ARM-GCIP Working Group (on which ARM is represented by R. G. Ellingson, P. J. Lamb, and D. A. Randall) and GCIP's funding of additional SGP CART rawinsonde observations during August 1994. This working group will be partially concerned with suggesting observational strategies for the SGP CART site for 1995 through 1996. Beyond that, the working group will benefit both programs by fostering the most cost-effective and efficient operations program possible. In the latter regard, the GCIP funding of additional rawinsonde soundings is expected to continue (and perhaps be enhanced) during 1995 through 1996. In addition, the GCIP component of NOAA's Climate and Global Change Program is currently considering a proposal from the SST to develop a capability for soil 
moisture monitoring for much of the total SGP CART domain that would fulfill the needs of both ARM and GCIP. If this proposal is funded, approximately one-third of the planned operational network will be installed and become operational in the second half of 1995 , with the remaining sites being established during 1996 and early 1997. This potentially important enhancement of the observational capabilities of the SGP CART site would strongly complement the ARM extended facilities in their aforementioned central role of facilitating the spatial integration of the surface heat, moisture, and momentum exchanges across the CART domain.

Somewhat less formal interactions with the Verification of the Origins of Rotation in Tornadoes Experiment (VORTEX) program, which were initiated during early 1994, are expected to continue in 1995 and 1996. These interactions led to funding by VORTEX of an enhancement of the spring 1994 SGP CART rawinsonde observations. As noted in Section 5, the ARM-VORTEX synergism planned for the spring 1995 IOP will include joint aircraft observations, as well as the rawinsonde enhancements. The joint aircraft observational capability stems from a collaborative proposal to NOAA/ Energy Research Laboratory (ERL) that was prepared by SST and VORTEX personnel. Aircraft-based instruments would measure the following parameters: upwelling and downwelling microwave brightness temperatures at low, middle, and high altitudes; upwelling and downwelling narrowband solar radiances above, in, and below clouds; cloud liquid water content; and in-cloud long-path extinction. Joint analyses of the resulting data sets are expected to extend into the second half of 1995 and at least early 1996. The dividends that are likely to accrue to the ARM Program would include improvement of inhomogeneous cloud models, an initial assessment of an ARM ergodic hypothesis (that time series measurements of cloud optical depth can be used to infer the instantaneous horizontal distribution of optical depth), and improved retrievals of total precipitable vapor and cloud liquid water path from special sensor microwave imager data.

The integration of ARM UAV operations into the SGP CART scientific mission was successfully initiated during the April 1994 IOP by using a small UAV (GNAT) that can only ascend to $6.7 \mathrm{~km}(\sim 22,000 \mathrm{ft})$. Because of delays in developing and testing the larger UAV (PERSEUS) that is needed to make ARM radiation measurements at higher elevations, further ARM UAV operations will likely be delayed until late 1995 and 1996. Those operations will be supported by climatological analysis of SGP historical cloud and tropospheric wind data performed by the SST and will likely include a dedicated UAV IOP.

One especially important use of the UAV platforms is expected to occur within an "anomalous cloud absorption experiment," which is now in the planning stages. This 
campaign-type experiment is being designed in response to very new evidence indicating substantial "anomalous" absorption of solar radiation by clouds. The early interpretations of the data involved (satellite top-of-the-atmosphere and land and ocean surface radiation measurements) suggest that existing climate models may underestimate the global mean absorption of solar radiation by clouds by as much as $25-40 \mathrm{~W} \mathrm{~m}^{-2}$ and may incorrectly assign that absorption to the surface. If ultimately sustained, this finding would require a significant rethinking of our understanding of atmospheric heating and may also render previous estimates of greenhouse-gas-induced warming even more uncertain than previously thought. The principal contributors to this effort to date (R. D. Cess, V. Ramanathan, J. Kiehl, and others) have concluded that the SGP ARM CART facility is ideally suited as a location for an experiment to quantify the processes involved. This experiment will obtain diverse radiative flux data from ground-based, satellite, and regular aircraft platforms, as well as from UAVs. The experiment will also be supported by historical cloud and storm frequency analyses performed by the SST. Although the initial component of this experiment possibly might be conducted during the spring IOP within the next six-month period covered by this mission plan (i.e., January through June 1995; see Section 5), that component more likely will be delayed until the fall IOP in the period of July through December 1995 . Such a delay would provide the opportunity to capitalize on the availability of the PERSEUS UAV, which is ideally suited to obtaining the measurements of higher altitude radiative flux that are needed. The follow-up components to this experiment will also likely occur during the fall 1995 IOP and in some 1996 IOPs. Certainly, the analysis of the data obtained will extend into late 1995 and most of 1996. The ensuing results may necessitate some fine-tuning of, and perhaps even more major modifications to, the routine procedures for SGP ARM CART observations of radiative flux and clouds. The opportunity for the SGP ARM CART facility to play a central role in this important experiment will be of considerable benefit to the overall ARM Program.

After mid-1995, the scientific operation of the SGP CART site will also benefit from guidance provided by a site advisory committee. The fundamental role of this committee will be to ensure that the operation of the site addresses the goals and objectives of the ARM Program (now being embodied in a formal Science Plan) to the fullest possible extent, including successfully adapting to changing circumstances and opportunities. Such a performance will ensure that the flows of data to the Science Team members are appropriate to their needs, of consistently high quality, and as continuous as possible. Because the membership of this advisory committee will be approximately equally divided between Science Team members and nonmembers, its guidance should reflect both the inherently more parochial concerns of the 
Science Team members and a broader global-change perspective emanating from the nonmembers.

The continued ramping up of SGP CART site (and allied) operations during 1995 and 1996, coupled with a parallel enhancement of the ability of the SDS to handle the resulting data streams, is thus expected to result in a mature pursuit of the scientific mission for this ARM locale by mid-1996. Among other things, this increase in operations should greatly facilitate the Science Team's use of the SGP CART data in an interactive real-time mode during late 1995 and 1996. One of the most unique potentials of the ARM Program will thus become more fully realized. 


\section{REFERENCES}

Cress, T., 1994, electronic mail from Cress (Battelle-Pacific Northwest Laboratory, Richland, Wash.) to D. Randall (Colorado State University, Fort Collins, Colo.), Sept. 9.

Davies-Jones, R., 1993, "Useful Formulas for Computing Divergence, Vorticity, and Their Errors from Three or More Stations," Monthly Weather Review 212:713-725.

Mace, G., et al., 1993, "Mesoscale Diagnostic Quantities from Arrays of Doppler Wind Profilers and Radiosondes," in Preprints of the Fourth Symposium on Global Change Studies, American Meteorological Society, Anaheim, Calif., pp. 58-63.

Michael, P., 1994, "Estimating Advective Tendencies from Field Measurements," Monthly Weather Review 122:2201-2209.

Schneider, J. M., et al., 1993, Site Scientific Mission Plan for Southern Great Plains CART Site: January-June 1994, ARM-94-001, Argonne National Laboratory, Argonne, Ill.

U.S. Department of Energy, 1990, Arm Program Plan, 1990, DOE/ER-0441, Washington, D.C. 